\title{
Cytoplasmic and Mitochondrial Calcium Signaling: A Two-Way Relationship
}

\author{
Benjamin Wacquier, ${ }^{1}$ Laurent Combettes, ${ }^{2}$ and Geneviève Dupont ${ }^{1}$ \\ ${ }^{1}$ Unit of Theoretical Chronobiology, Faculté des Sciences, Université Libre de Bruxelles (ULB) CP231, B1050 \\ Brussels, Belgium \\ ${ }^{2}$ UMR-S 1174 Inserm, Université Paris-Sud, 91405 Orsay, France \\ Correspondence: gdupont@ulb.ac.be
}

Intracellular $\mathrm{Ca}^{2+}$ signals are well organized in all cell types, and trigger a variety of vital physiological processes. The temporal and spatial characteristics of cytosolic $\mathrm{Ca}^{2+}$ increases are mainly governed by the fluxes of this ion across the membrane of the endoplasmic/sarcoplasmic reticulum and the plasma membrane. However, various $\mathrm{Ca}^{2+}$ transporters also allow for $\mathrm{Ca}^{2+}$ exchanges between the cytoplasm and mitochondria. Increases in mitochondrial $\mathrm{Ca}^{2+}$ stimulate the production of ATP, which allows the cells to cope with the increased energy demand created by the stimulus. Less widely appreciated is the fact that $\mathrm{Ca}^{2+}$ handling by mitochondria also shapes cytosolic $\mathrm{Ca}^{2+}$ signals. Indeed, the frequency, amplitude, and duration of cytosolic $\mathrm{Ca}^{2+}$ increases can be altered by modifying the rates of $\mathrm{Ca}^{2+}$ transport into, or from, mitochondria. In this review, we focus on the interplay between mitochondria and $\mathrm{Ca}^{2+}$ signaling, highlighting not only the consequences of cytosolic $\mathrm{Ca}^{2+}$ changes on mitochondrial $\mathrm{Ca}^{2+}$, but also how cytosolic $\mathrm{Ca}^{2+}$ dynamics is controlled by modifications of the $\mathrm{Ca}^{2+}$-handling properties and the metabolism of mitochondria.

M itochondria are organelles found in nearly all cell types of eukaryotic organisms, with the notable exception of erythrocytes (Repsold and Joubert 2018). They are characterized by two membranes, the inner mitochondrial membrane (IMM) that encloses the mitochondrial matrix and the outer mitochondrial membrane (OMM). These two membranes are a few nanometers apart and delimit the so-called intermembrane space (IMS). The OMM is smooth and highly permeable to most solutes, whereas the IMM is impermeable. Besides, the IMM is folded into cristae, allowing to increase the sur- face of this membrane (El-Hattab et al. 2018). Mitochondria form unconnected, functionally distinct entities (Collins et al. 2002) and their number varies from tens (in lymphocytes [Potter and Ward 1942]) to thousands (in hepatocytes) per cell (Weibel et al. 1969). They are usually considered as $1-\mu \mathrm{m}$ wide spherocylinders, varying in length from 1 to $10 \mu \mathrm{m}$. These organelles of widely different sizes also display heterogenous cellular distribution, with a denser aggregation of mitochondria around the nucleus than in the cell periphery (Collins et al. 2002). Heterogeneity is further amplified by the

Editors: Geert Bultynck, Martin D. Bootman, Michael J. Berridge, and Grace E. Stutzmann

Additional Perspectives on Calcium Signaling available at www.cshperspectives.org

Copyright (C 2019 Cold Spring Harbor Laboratory Press; all rights reserved; doi: 10.1101/cshperspect.a035139

Cite this article as Cold Spring Harb Perspect Biol 2019;11:a035139 
B. Wacquier et al.

dynamic behavior of these organelles. Indeed, mitochondria continuously move along the cytoskeleton. They are able to grow, divide, or fuse with each other (Wang et al. 2012). Moreover, when submitted to stressful conditions, they can connect and form a network that allows a better adaptation to maintain cellular homeostasis (Zemirli et al. 2018).

The roles of mitochondria are numerous and notably include cell cycle regulation, apoptosis, bioenergetics, and also $\mathrm{Ca}^{2+}$ homeostasis (Murphy and Hartley 2018). Indeed, although $\mathrm{Ca}^{2+}$ signaling in nonexcitable cells mainly involves fluxes between the cytosol, the plasma membrane (PM) and the endoplasmic reticulum ([ER], the main $\mathrm{Ca}^{2+}$ storage of the cell), mitochondria, as well as other organelles such as lysosomes, are able to alter cytosolic $\mathrm{Ca}^{2+}$ signals (Dupont et al. 2011; Patel and Muallem 2011). At rest, the $\mathrm{Ca}^{2+}$ concentration inside mitochondria is of the same order as that in the cytosol $(\sim 0.1$ $\mu \mathrm{M})$. The close apposition between mitochondria and ER membranes favors $\mathrm{Ca}^{2+}$ exchanges between these organelles (Rizzuto et al. 1998; Csordás et al. 1999, 2010). Cytosolic $\mathrm{Ca}^{2+}$ increases, mostly as a result of the release of $\mathrm{ER} \mathrm{Ca}^{2+}$ through the inositol 1,4,5-trisphosphate receptor $\left(\mathrm{IP}_{3} \mathrm{R}\right)$, can indeed be transmitted into mitochondria via the different transporters located in the mitochondrial membranes. As mitochondria can take up large amounts of cytosolic $\mathrm{Ca}^{2+}$, this sequestration modifies the quantitative and dynamic characteristics of $\mathrm{Ca}^{2+}$ signaling in the cytosol (Nicholls and Chalmers 2004).

$\mathrm{Ca}^{2+}$ is an essential activator of mitochondrial metabolism and stimulates the synthesis of ATP molecules (Fig. 1A). Notably, $\mathrm{Ca}^{2+}$ activates three dehydrogenases involved in the Krebs cycle (Rizzuto et al. 2012). This cycle oxidizes acetyl-coenzyme A, typically issued from pyruvate generated by glycolysis. This oxidation is coupled with the reduction of $\mathrm{NAD}^{+}$into $\mathrm{NADH}$. NADH molecules in turn transfer their electrons to the electron transport chain (ETC). The four first complexes of the ETC (I-IV) use the energy provided by electrons to export protons from the matrix into the IMS, hence generating an important transmembrane potential difference between the matrix and the IMM
$(\Delta \Psi)$. The resting mitochondrial $\Delta \Psi$ is around 150-160 mV, negative inside. Complex V, which is the $\mathrm{F}_{1} \mathrm{~F}_{0}$-ATP synthase, consumes the energy provided by the electrochemical gradient to synthesize ATP (Murphy and Hartley 2018). The $\Delta \Psi$ is crucial not only for energetic production, but also for $\mathrm{Ca}^{2+}$ fluxes in and out of mitochondria. Indeed, the $\mathrm{Ca}^{2+}$ transporters through the IMM are electrogenic and dependent on the electrochemical gradient of $\mathrm{Ca}^{2+}$ between the cytosol and the mitochondrial matrix. Thus, changes in $\Delta \Psi$ affect the balance between influx and efflux of mitochondrial $\mathrm{Ca}^{2+}$. Interestingly, this is not the case for transporters in the ER where fluxes of protons and other monovalent cations compensate the potential variations due to $\mathrm{Ca}^{2+}$ transport (Meissner 1981). Perturbations in mitochondrial $\mathrm{Ca}^{2+} \mathrm{dy}-$ namics can be associated with pathological conditions: disturbances in $\mathrm{Ca}^{2+}$ fluxes, in molecular mitochondrial components, or in the distance between mitochondria and ER can lead to impaired bioenergetics of the cell or cellular death (Contreras et al. 2010; Naon and Scorrano 2014; Mishra 2016; Wang et al. 2016). $\mathrm{Ca}^{2+}$ thus constitutes a signal of life and death that is finely tuned by molecular and geometric parameters (Berridge et al. 1998).

In this review, we focus on the interplay between mitochondria and $\mathrm{Ca}^{2+}$ signaling, highlighting not only the consequences of cytosolic $\mathrm{Ca}^{2+}$ changes on mitochondrial $\mathrm{Ca}^{2+}$, but also how cytosolic $\mathrm{Ca}^{2+}$ dynamics can be altered by modifications of the $\mathrm{Ca}^{2+}$-handling properties and the metabolism of mitochondria. We first list the main mitochondrial $\mathrm{Ca}^{2+}$ transporters and report evidence of the impact of their activity on mitochondrial and cytosolic $\mathrm{Ca}^{2+}$ dynamics. We next focus on the mitochondrial permeability transition pore (mPTP) and on its less well-established participation in mitochondrial $\mathrm{Ca}^{2+}$ dynamics. The bidirectional relation between $\mathrm{Ca}^{2+}$ signaling and metabolism, the main physiological target of mitochondrial $\mathrm{Ca}^{2+}$ increases, is then discussed. In the last section, we report observations highlighting the importance of the spatial arrangement of the $\mathrm{Ca}^{2+}$ transporters located in the ER and in the mitochondrial membranes. 
Cytoplasmic and Mitochondrial Calcium Signaling

\section{MITOCHONDRIAL $\mathrm{Ca}^{2+}$ TRANSPORTERS}

On cell stimulation, cytoplasmic $\mathrm{Ca}^{2+}$ increases are transmitted to mitochondria. $\mathrm{Ca}^{2+}$ ions need to cross two membranes to pass from the cytosol into the mitochondrial matrix (Fig. 1D). $\mathrm{Ca}^{2+}$ first passes through the OMM via a highly expressed voltage-dependent anion-selective channel (VDAC). This channel behaves as a dif- fusion pore that is permeable to ions and small hydrophilic metabolites, thus accounting for the high permeability of the OMM. VDAC exists in three isoforms $(1,2,3)$ and displays multiple conductance states (Shoshan-Barmatz et al. 2018). The so-called "closed" states (i.e., the states with the lower permeability to metabolites) have the highest permeability to $\mathrm{Ca}^{2+}$ (Tan and Colombini 2007). In HeLa cells stim-

A

Cytosol

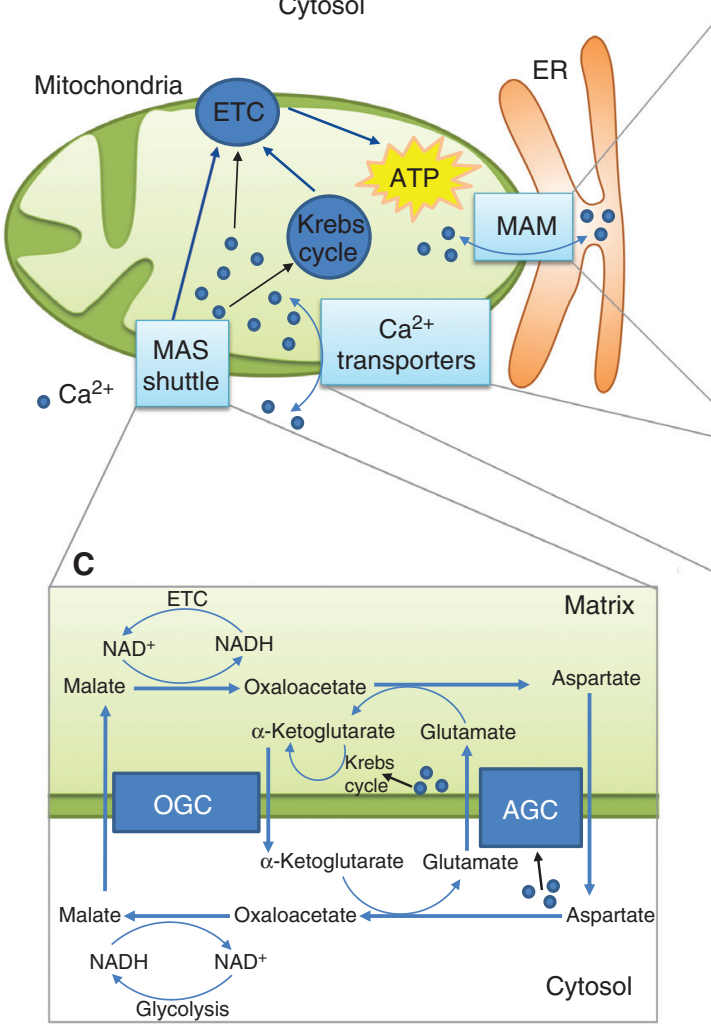

B

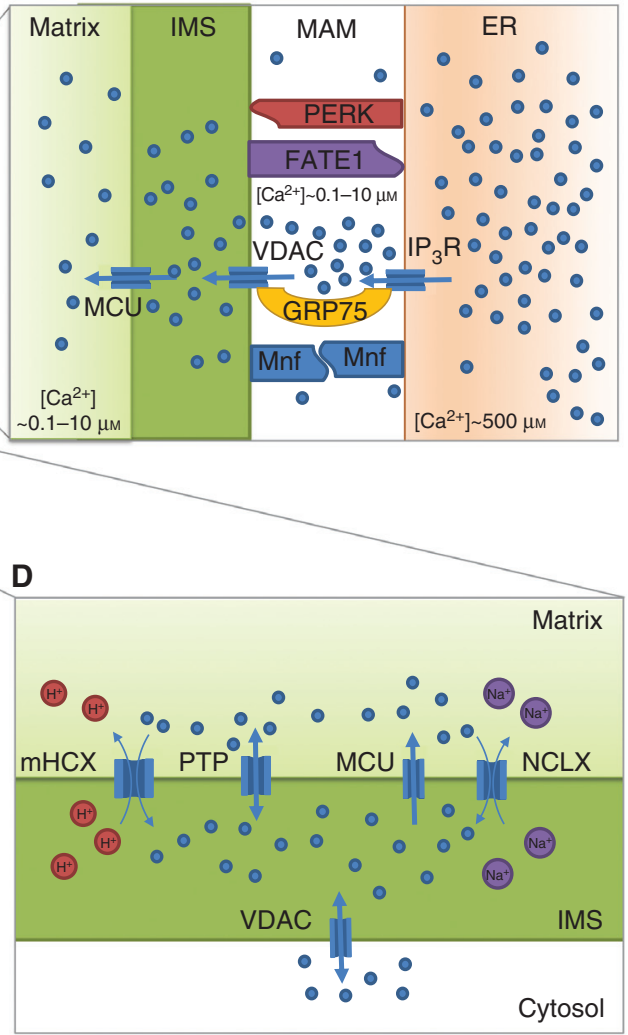

Figure 1. Schematic representation of some key aspects of mitochondrial $\mathrm{Ca}^{2+}$ dynamics and of the interplay between $\mathrm{Ca}^{2+}$ and mitochondrial metabolism $(A)$. $\mathrm{Ca}^{2+}$ exchanges between the cytosol and mitochondria allow the activation of mitochondrial metabolism, by boosting the Krebs cycle and the electron transport chain (ETC). (B) Membranes of the ER and the mitochondria are linked via tethering proteins (PERK, FATE, GRP75, Mfn, and others not indicated in this simplified scheme) to form mitochondria-associated membranes (MAMs). These membranes delimit areas where $\mathrm{Ca}^{2+}$ can reach high concentrations. $(C)$ The electrons of the NADH produced in the cytosol by glycolysis are transferred into mitochondria by the malate-aspartate shuttle (MAS). The aspartateglutamate carrier (AGC) of the MAS is activated by cytosolic $\mathrm{Ca}^{2+}$. At high mitochondrial $\mathrm{Ca}^{2+}$ concentration, the activation of the Krebs cycle consumes $\alpha$-ketoglutarate and limits the impact of the MAS. OGC stands for oxoglutarate carrier (see text for details). (D) $\mathrm{Ca}^{2+}$ has to cross two membranes to enter inside a mitochondrion: the outer mitochondrial membrane (OMM) and the inner mitochondrial membrane (IMM). The first one is passed via a voltage-dependent anion-selective channel (VDAC), a nonselective channel. More specific $\mathrm{Ca}^{2+}$ transporters are involved in the crossing of the IMM (see text for details). 
B. Wacquier et al.

ulated by histamine, overexpression of the three VDAC isoforms induces an increase in the mitochondrial $\mathrm{Ca}^{2+}$ levels, whereas silencing their expression tends to decrease mitochondrial $\mathrm{Ca}^{2+}$ uptake (de Stefani et al. 2012). Similarly, in mouse embryonic fibroblasts, the knocking out of VDAC1 limits agonist-induced mitochondrial $\mathrm{Ca}^{2+}$ uptake (Monaco et al. 2015). In heart cells, VDAC2-dependent mitochondrial $\mathrm{Ca}^{2+}$ uptake plays a critical modulatory role in the regulation of cardiac rhythmicity, most probably by controlling the spatial and temporal extent of the $\mathrm{Ca}^{2+}$ increases in the cytosol (Shimizu et al. 2015). However, it is most often assumed that in physiological conditions the $\mathrm{Ca}^{2+}$ transport via VDAC across the OMM is kinetically not limiting.

The transfer of $\mathrm{Ca}^{2+}$ from the IMS into the mitochondrial matrix is much more complex. Various transporters are indeed expressed in the IMM (Fig. 1D). $\mathrm{Ca}^{2+}$ ions enter into mitochondria through a channel known as the mitochondrial $\mathrm{Ca}^{2+}$ uniporter (MCU). The MCU is located in the IMM, is highly selective to $\mathrm{Ca}^{2+}$, and is inhibited by ruthenium red. The opening of the uniporter has a sigmoidal dependence on cytosolic $\mathrm{Ca}^{2+}$, and is characterized by a rather low affinity for $\mathrm{Ca}^{2+}\left(K_{d} \sim 2-10 \mu \mathrm{M}\right)$ (Mallilankaraman et al. 2012; Csordás et al. 2013; Paillard et al. 2017). However, the effective dependence of the MCU on $\mathrm{Ca}^{2+}$ is intricate, as when $\mathrm{Ca}^{2+}$ enters into the mitochondrial matrix, it provokes a decrease in $\Delta \Psi$ that diminishes the driving force for $\mathrm{Ca}^{2+}$ entry. Although the existence of a $\mathrm{Ca}^{2+}$ uniporter was postulated for a few decades thanks to functional studies of mitochondrial $\mathrm{Ca}^{2+}$ uptake, its molecular identity was identified much later as the $40-\mathrm{kDa} \mathrm{MCU}$ (Baughman et al. 2011; de Stefani et al. 2011). MCU oligomers form a highly selective $\mathrm{Ca}^{2+}$ pore that is part of a multiprotein complex composed of a large number of regulators, notably the mitochondria $\mathrm{Ca}^{2+}$ uptake proteins $1,2,3$ (MICU 1,2,3) and the essential MCU regulator (EMRE). These regulators allow a fine tuning of the opening of the MCU pore (Mammucari et al. 2018; Nemani et al. 2018; Penna et al. 2018) and modulate the sigmoidal dependence on $\mathrm{Ca}^{2+}$ of the MCU (Csordás et al. 2013; Patron et al.
2014). Specific stoichiometries between the MCU and its regulators may be responsible for the observed tissue-specific differences of activities of the uniporter, and explains, for example, the variation in $\mathrm{Ca}^{2+}$ dynamics observed in mitochondria of heart and liver (Paillard et al. 2017; Wacquier et al. 2017). Indeed, as MICU1 is less expressed in cardiomyocytes, the $\mathrm{Ca}^{2+}$ uptake rate is higher at low cytosolic $\mathrm{Ca}^{2+}$ concentrations, but smaller at high cytosolic $\mathrm{Ca}^{2+}$ levels, as compared with hepatocytes that express much more MICU1. This tissue-specific MICU1:MCU expression ratio is highly relevant as heart cells characterized by a liver-like MICU1:MCU expression ratio display contractile dysfunction (Paillard et al. 2017). Interestingly, in modeling approaches, it is possible to provide a unifying description of mitochondrial $\mathrm{Ca}^{2+}$ dynamics in different cell types by taking into account the level of expression of the MCU (which is lower in heart cells [Fieni et al. 2012]) and the MICU1:MCU expression ratio (Wacquier et al.2017). As a matter of fact, the regulation of the MCU is highly sophisticated and is covered in detail in recent reviews (Giorgi et al. 2018; Nemani et al. 2018; Wang et al. 2018). Although the MCU is the predominant $\mathrm{Ca}^{2+}$ import mechanism, other transport systems have been reported to enable mitochondrial $\mathrm{Ca}^{2+}$ uptake. Such systems include mitochondrial ryanodine receptors in cardiomyocytes and neurons (Jakob et al. 2014), mitochondrial connexin 43 in cardiac cells (Gadicherla et al. 2017), and the rapid mode of $\mathrm{Ca}^{2+}$ uptake (RaM) in cardiomyocytes and hepatocytes (Buntinas et al. 2001). However, the exact roles of these channels remain elusive.

$\mathrm{Ca}^{2+}$ is extruded from mitochondria via exchangers. The IMM has two main types of $\mathrm{Ca}^{2+}$ exchangers: a $\mathrm{H}^{+} / \mathrm{Ca}^{2+}$ exchanger (mHCX, expressed mainly in nonexcitable cells) and $\mathrm{Na}^{+} /$ $\mathrm{Ca}^{2+}$ exchanger (NCX, expressed mainly in excitable cells). The mNCX activity is attributed to the protein NCLX (Palty et al. 2010). This transporter is generally thought to import three $\mathrm{Na}^{+}$ in exchange for one $\mathrm{Ca}^{2+}$, although the exact stoichiometry of this transporter is still controversial (Kim et al. 2013). NCLX is electrogenic and its activity depends on $\Delta \Psi$. It is noncoop- 
eratively activated by mitochondrial $\mathrm{Ca}^{2+}$, whereas it is cooperatively regulated by $\mathrm{Na}^{+}$, with a Hill coefficient of 2 (Wingrove and Gunter 1986). Interestingly, it has been shown that the NCLX displays a reverse transport mode. This happens in depolarized mitochondria, under the control of the protein mitofusin 2. This reverse mode could be relevant in pathological conditions when $\Delta \Psi$ is transiently or chronically collapsed, as $\mathrm{Ca}^{2+}$ uptake via the MCU is dependent on $\Delta \Psi$ (Samanta et al. 2018).

The nature of the $\mathrm{mHCX}$ is still an ongoing and controversial issue. Some reports suggest that the leucine zipper EF hand-containing transmembrane (LETM1) protein is responsible for this activity. Indeed, in vitro, LETM1 favors an electrogenic exchange of $\mathrm{H}^{+}$and $\mathrm{Ca}^{2+}$ (Tsai et al. 2014). Additionally, HeLa cells that do not express LETM1 show higher mitochondrial $\mathrm{Ca}^{2+}$ levels, highlighting the importance of LETM1 in $\mathrm{Ca}^{2+}$ efflux (Shao et al. 2016). However, other studies indicate that mitochondrial $\mathrm{Ca}^{2+}$ efflux is mediated by the NCLX and not by LETM1 in HeLa cells. Indeed, in cells stimulated by histamine to generate cytosolic and mitochondrial $\mathrm{Ca}^{2+}$ signals, an overexpression of LETM1 does not change the rate of $\mathrm{Ca}^{2+}$ efflux from mitochondria (de Marchi et al. 2014b). Other groups also suggest that LETM1 is a $\mathrm{K}^{+}$/ $\mathrm{H}^{+}$exchanger. In this case, LETM1 would alter NCLX activity, maybe by changing the osmotic balance (Austin et al. 2017).

Through the action of uniporter and the exchangers, cytosolic $\mathrm{Ca}^{2+}$ signals are transmitted to mitochondria. $\mathrm{Ca}^{2+}$ oscillations can thus be observed in these organelles (Ishii et al. 2006). In some cell types, mitochondria are able to integrate the cytosolic $\mathrm{Ca}^{2+}$ oscillations. For example, in cat ventricular myocytes, the cytosolic oscillations induce a progressive elevation of the mitochondrial $\mathrm{Ca}^{2+}$ level (Sedova et al. 2006). In hepatocytes, the mitochondrial $\mathrm{Ca}^{2+}$ signals themselves are integrated into different levels of activation of metabolism (Hajnóczky et al. 1995). The physiological consequences of these increases in mitochondrial $\mathrm{Ca}^{2+}$ have been much described (Jouaville et al. 1999; Denton 2009; Griffiths and Rutter 2009; Williams et al. 2015). Less emphasis has been put on the fact that mitochondria alter $\mathrm{Ca}^{2+}$ signaling in the cytosol, both by sequestering and releasing $\mathrm{Ca}^{2+}$. Experiments and mathematical models highlight well-defined differences in the phases of the $\mathrm{Ca}^{2+}$ oscillations in different compartments (ER, cytosol, and mitochondria). Interestingly, it appears that between two successive cytosolic spikes of the oscillations, mitochondria are slowly releasing $\mathrm{Ca}^{2+}$ while the ER is still replenishing. It suggests that mitochondria are able to gradually release the $\mathrm{Ca}^{2+}$ accumulated during a single spike, allowing the reactivation of the $\mathrm{IP}_{3} \mathrm{R}$, and the triggering of a new spike (Ishii et al. 2006; Wacquier et al. 2016). Thus, $\mathrm{Ca}^{2+}$ release from mitochondria is in part responsible for the pacemaker $\mathrm{Ca}^{2+}$ increase in the cytosol that progressively activates $\mathrm{IP}_{3} \mathrm{R}$ and stimulates $\mathrm{Ca}^{2+}$ release from the ER, before the onset of each spike of the oscillations. This is supported by data obtained in different cell types when using inhibitors of the MCU or of the NCLX. For example, in HeLa cells stimulated by histamine, siRNA-mediated reduction of MCU expression tends to slow down the cytosolic oscillations (Fig. $2 \mathrm{~A}, \mathrm{~B})$. This is explained by a lower accumulation of $\mathrm{Ca}^{2+}$ in mitochondria, and thus a weaker subsequent reactivation of $\mathrm{IP}_{3} \mathrm{R}$ (Wacquier et al. 2016). In the same cell type, the addition of CGP37157, an NCLX inhibitor, favors fast oscillations (Hernández-SanMiguel et al. 2006). A more drastic impact of altering MCU expression is observed in mast cells, in which the proinflammatory leukotriene $\mathrm{C} 4$ signal induces damped $\mathrm{Ca}^{2+}$ oscillations in the cytosol. If the MCU is knocked down in these cells, the damping is hastened considerably (Samanta et al. 2014). Mitochondria also have a significant impact on the electric activity of heart cells. This activity is attributable to $\mathrm{Ca}^{2+}$ release from the sarcoplasmic reticulum (SR) and induces spontaneous heartbeats. Such a disturbance increases the risk of arrhythmia. In cardiomyocytes, this spontaneous electrical activity is sensitive to perturbations of the mitochondrial $\mathrm{Ca}^{2+}$ fluxes. Inhibition of the MCU by Ru360 indeed decreases the frequency of these beats. In a similar way, inhibiting the NCLX by CGP37157 completely inhibits spontaneous $\mathrm{Ca}^{2+}$ release, and the associated beats (Xie et al. 2018). 
B. Wacquier et al.
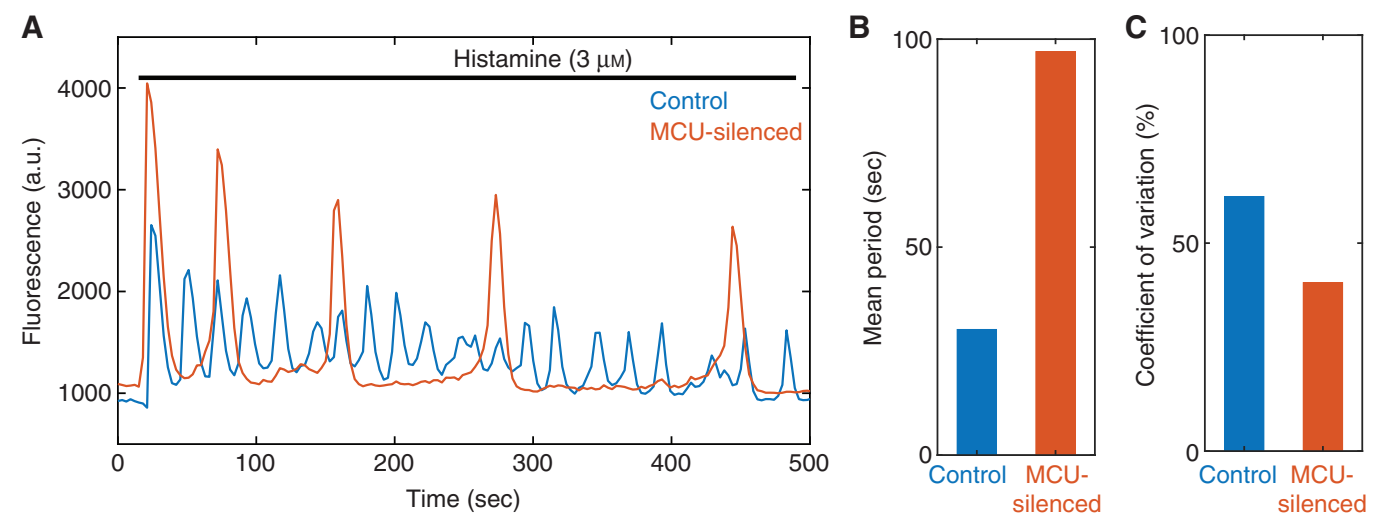

Figure 2. Impact of the mitochondrial $\mathrm{Ca}^{2+}$ uniporter (MCU)-silencing on cytosolic $\mathrm{Ca}^{2+}$ oscillations. (A) Cytosolic $\mathrm{Ca}^{2+}$-probe fluorescence in HeLa cells stimulated with $3 \mu \mathrm{M}$ histamine. The $\mathrm{Ca}^{2+}$ oscillations induced by histamine are drastically different in control cells (blue) compared with those in MCU-silenced cells (red), thus showing how $\mathrm{Ca}^{2+}$ handling by mitochondria can affect cytosolic $\mathrm{Ca}^{2+}$ signals. $(B)$ Mean period of the $\mathrm{Ca}^{2+}$ oscillations shown in panel $A$. In MCU-silenced cells, the period of the cytosolic $\mathrm{Ca}^{2+}$ oscillations is much increased, as compared with control cells. $(C)$ Coefficient of variation (CV) (standard deviation/mean) of the time interval between two successive peaks of these oscillations. The MCU-silenced cells display a lower CV, which is associated with more regular spikes. (The data are taken, with permission, from Wacquier et al. 2016.)

In HeLa cells, individual mitochondria of one single cell display heterogeneities in their $\mathrm{Ca}^{2+}$ profiles following a stimulation by histamine (Suzuki et al. 2014). It remains to be established whether such differences are the result of variations in the levels of expression of $\mathrm{Ca}^{2+}$ transporters, in mitochondrial $\mathrm{Ca}^{2+}$ buffering strengths, or in ER-mitochondria coupling. However, modeling approaches predict that changes in the mitochondrial properties (notably $\mathrm{Ca}^{2+}$ buffering or MCU level) greatly alter the amplitude of mitochondrial $\mathrm{Ca}^{2+}$ responses. In addition to these heterogeneities, mitochondria are likely to be the source of molecular noise because of their small volume. This is visible experimentally and in stochastic models ( $\mathrm{Lu}$ et al. 2016; Gonze et al. 2018). Fluctuations in mitochondrial $\mathrm{Ca}^{2+}$ concentrations can be transmitted to rates of $\mathrm{Ca}^{2+}$ transport, and thus to cytosolic $\mathrm{Ca}^{2+}$ signals. In agreement with this hypothesis, considering mitochondria in stochastic models for $\mathrm{Ca}^{2+}$ oscillations increases their coefficient of variation ([CV] defined as the ratio between the standard deviation and the mean of the interspikes intervals) of $\sim 20 \%$ (Gonze et al. 2018). MCU-silenced HeLa cells display $\mathrm{Ca}^{2+}$ oscillations characterized by a lower
CV than those of a control case (Fig. 2C; Wacquier et al. 2016). This effect is attributable both to an increase of the period, and to stochastic disturbances in $\mathrm{Ca}^{2+}$ exchanges. In other words, the coupling between cytosolic and mitochondrial $\mathrm{Ca}^{2+}$ signaling has a cost in terms of the regularity of the cytosolic $\mathrm{Ca}^{2+}$ spikes.

\section{MITOCHONDRIAL PERMEABILITY TRANSITION PORE}

Under some circumstances such as mitochondrial $\mathrm{Ca}^{2+}$ overload or metabolic stress, a sudden increase in the permeability of the IMM can be observed. This phenomenon, called permeability transition (PT), is imputed to the opening of a nonselective channel, the mitochondrial permeability transition pore (mPTP). A sustained opening of this pore leads to the leakage of ions, metabolic molecules, and proapoptotic agents, resulting in mitochondrial swelling, dissipation of the electrochemical gradient, impaired ATP production, and, finally, cell death (Giorgio et al. 2018). The properties, and the regulation, of the $\mathrm{mPTP}$ have been highlighted in the late 1970s by the famous works of Hunter et al. (1976) and Hunter and Haworth (1979a,b,c). The opening 
Cytoplasmic and Mitochondrial Calcium Signaling

of the mPTP is favored by $\mathrm{Ca}^{2+}$, extramitochondrial $\mathrm{pH}$, fatty acids, cyclophilin $\mathrm{D}$ protein (CyPD), reactive oxygen species (ROS), or inorganic phosphates. It is inhibited by other divalent ions $\left(\mathrm{Mg}^{2+}, \mathrm{Sr}^{2+}, \mathrm{Mn}^{2+}\right)$, nucleotides, matrix acidification, $\Delta \Psi$, or cyclosporin $\mathrm{A}$ (CsA), a drug widely used to study the MPTP (Szabo and Zoratti 2014). Interestingly, mitochondrial $\mathrm{Ca}^{2+}$ is necessary for $\mathrm{MPTP}$ opening: in a suspension of mitochondria, the opening of the PTP (assessed by the swelling of mitochondria) can be triggered by drugs such as phenylarsine oxide (PhAsO) or $p$-hydroxyphenylglyoxal $(\mathrm{OH}-$ PGO). In the presence of the membrane permeant BAPTA-AM, responsible for mitochondrial $\mathrm{Ca}^{2+}$ chelation, the PhAsO- or OH-PGO-induced opening of the pore is blocked. This pinpoints the crucial role of mitochondrial $\mathrm{Ca}^{2+}$, even in residual amounts. However, matrix $\mathrm{Ca}^{2+}$ is by itself not always sufficient to elicit PTP opening, as no swelling is noticed in the same experiments without $\mathrm{PhAsO}$ or $\mathrm{OH}$ PGO addition (Giorgio et al. 2018).

However, despite its early discovery and characterization, the MPTP is still subject to intensive research as its molecular nature was unsolved until recently. It was long considered that the MPTP forms at a contact site between the IMMs and the OMMs, as a complex between the VDAC and the adenine nucleotide transporter (ANT). However, this idea was rejected on the basis of experiments involving genetic deletion of these components: mitochondria lacking ANT or VDAC are still able to undergo a PT inhibited by CsA (Kokoszka et al. 2004; Baines et al. 2007). The involvement of the $\mathrm{F}_{1} \mathrm{~F}_{0}$-ATP synthase in PT was then proposed, because CyPD, an inducer of the MPTP, was found to bind this complex and to promote its partial deactivation, an effect that can be removed by CsA (Giorgio et al. 2009). This has been validated by experiments using purified dimers of ATP synthase reconstituted in lipid bilayers. In such a system, it is possible to trigger the opening of a channel, the electrophysiological properties of which are similar to those of the MPTP (Giorgio et al. 2013).

The molecular identification of the PTP allowed a better understanding of the interplay between the inducers of PT and the pore itself. For example, the reversible protonation of a histidine residue, located in the oligomycin sensitivity-conferring protein (OSCP) unit of the ATP synthase, has been shown to inhibit the opening of the pore (Antoniel et al. 2018). The $\mathrm{Ca}^{2+}$-binding site of ATP synthase, which allows the opening of the pore, has recently been identified. Binding changes the conformation of the complex, leading to the opening of the pore (Giorgio et al. 2017).

Despite its recent molecular identification, the exact location of the pore in the ATP synthase still constitutes an ongoing issue. Two hypotheses emerge on this topic: the pore forms itself either between two monomers of ATP synthase or in the $\mathrm{C}$ subunit ring of the enzyme (the main transmembrane subunit forming the $\mathrm{F}_{0}$ rotor). In both cases, it seems that a dimerization step is necessary: ATP synthases purified in a lipid bilayer do not display any conductivity in their monomeric form, but are permeable when assembled in dimers (Giorgio et al. 2013, 2017). It has been further suggested that the opening of the pore is associated with the dissociation of the dimers, as the opening of the mPTP leads to an increase of the monomer/dimer ratio. As $\mathrm{C}$ subunits appear to play a role in this dissociation, the opening of the ATP synthase dimers would be a result of a reorganization of the $\mathrm{C}$ ring (Bonora et al. 2013, 2017). Nevertheless, it has also been reported that the opening of the PTP can occur even in the absence of $\mathrm{C}$ subunits (He et al. 2017).

As mentioned above, the opening of the mPTP is favored by ROS (Bernardi et al. 2006), which can be generated as a consequence of ATP production by mitochondria and are important for cellular signaling, although they also contribute to oxidative stress and cellular damage (Feissner et al. 2009). Mitochondrial $\mathrm{Ca}^{2+}$ overload increases ROS production through complex II disintegration. These $\mathrm{Ca}^{2+}$-induced ROS subsequently activate mPTP opening and cellular death (Hwang et al. 2014). On the other hand, depending on the targeted protein, the type and concentration of ROS, and the duration of exposure, ROS can stimulate or inhibit $\mathrm{Ca}^{2+}$ signaling (Csordás and Hajnóczky 2009; Tadic 
B. Wacquier et al.

et al. 2014). For example, at the ER-mitochondria interface, $\mathrm{H}_{2} \mathrm{O}_{2}$ generated by $\mathrm{Ca}^{2+}$ overload modulates agonist-induced $\mathrm{Ca}^{2+}$ release and oscillations (Booth et al. 2016). This effect may be because of changes in the redox environment and thus in the redox state of $\mathrm{IP}_{3} \mathrm{R} 1$ (Joseph et al. 2018). There is thus an intricate cross talk between $\mathrm{Ca}^{2+}$ signals, ROS production, and mPTP opening, which is frequently dysregulated in severe human pathologies such as cardiovascular diseases, cancer, and neurodegeneration (Feissner et al. 2009; Marchi et al. 2017).

The physiological role of the MPTP depends on its conductance state. Indeed, the mPTP can open in two states: low and high conductance modes (Fig. 3A). The latter one is well known and occurs in stressful or pathological conditions. In this case, the pore becomes permeable to large molecules $(<1.5 \mathrm{kDa})$. This opening is physiologically irreversible, leads to the dissipation of $\Delta \Psi$, and triggers cell apoptosis (Brenner and Moulin 2012). Pathological consequences linked to the MPTP are usually associated with increased $\mathrm{Ca}^{2+}$ uptake and overload, which tend to favor the opening of the pore. For example, the $\mathrm{MPTP}$ has a role in the ischemia/reperfusion injury (I/RI): when the blood flow in a vessel is occluded and then restored, an infarct, the size of

A

A Low conductance mode

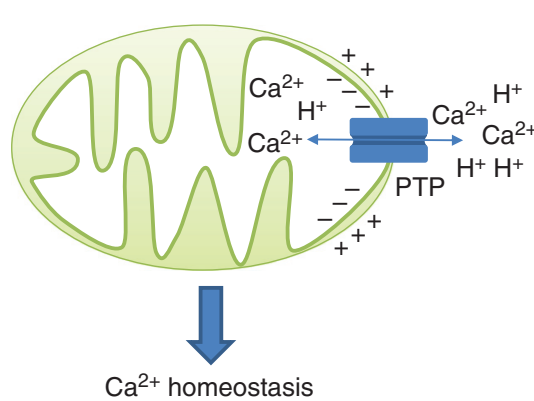

B

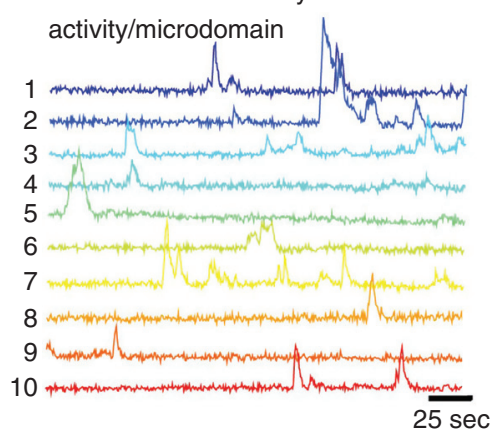

$\mathrm{Ca}^{2+}, \mathrm{CypD}, \mathrm{Pi}, \mathrm{ROS}$

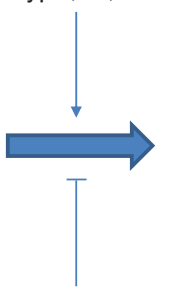

$\mathrm{H}^{+}, \Delta \psi, \mathrm{CsA}$
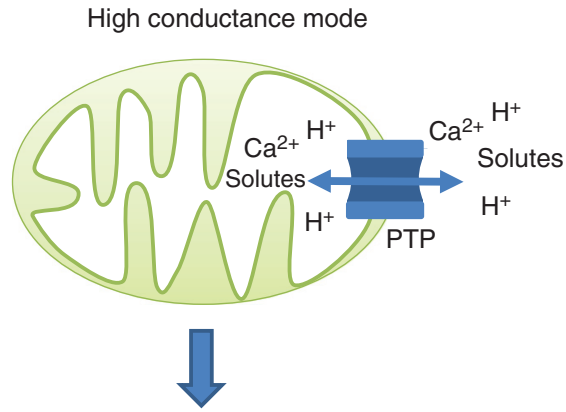

Loss of membrane voltage cellular death

C

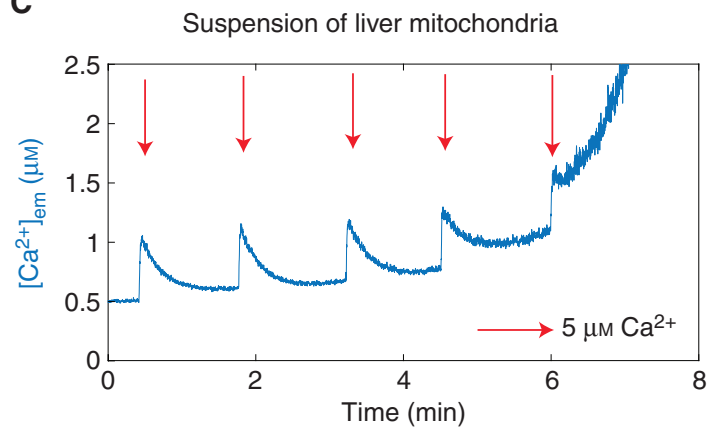

Figure 3. The mitochondrial permeability transition pore (mPTP) can open in two conductance modes. (A) Schematic representations of the mPTP opening in the low (left) and in the high (right) conductance modes. $(B)$ Experimental observation of transient openings of the MPTP in the low conductance mode. Each trace shows the local $\mathrm{Ca}^{2+}$ concentration in a well-defined microdomain of an astrocyte. These transient elevations are attributed to the MPTP as adding CsA decreases the probability of occurrence of these events. The data are from Agarwal et al. (2017) with permission. (C) $\mathrm{Ca}^{2+}$ measured in the extramitochondrial medium of a suspension of mitochondria extracted from hepatocytes. After several $\mathrm{Ca}^{2+}$ additions in the medium (arrows), the mPTP opens in its high conductance mode. This is visible thanks to the increase in $\mathrm{Ca}^{2+}$ in the medium, as a result of the leakage of mitochondrial $\mathrm{Ca}^{2+}$ through the $\mathrm{mPTP}$ in its high conductance state. See Wacquier et al. (2017) for experimental methods. 
which is reduced by inhibiting the MPTP, appears (Bulluck et al. 2016). This effect is linked to mitochondrial $\mathrm{Ca}^{2+}$ influx as the inhibition of the MCU protects neurocytes from I/RI (Yu et al. 2016). As the $C$ subunit of the ATP synthase seems to be a core component of the mPTP, it is likely to play an important role in I/RI (Morciano et al. 2015). Drugs targeting the C subunits have recently been developed. By administrating these compounds in the reperfusion phase, the apoptotic rate of the cells is indeed attenuated (Morciano et al. 2018). Hypersensitivity of the $\mathrm{MPTP}$ is also encountered in neurodegenerative diseases such as Alzheimer's disease, Huntington's disease, or Parkinson's disease (Pérez and Quintanilla 2017). In contrast, a decrease in the propensity of the pore to switch to an open state can lead to cancers (Rasol et al. 2010).

However, it seems than the PTP is not only associated with pathological conditions, in particular in its low conductance mode. This mode occurs in a transient and flickering way. In this state, the MPTP is only permeable to small ions $\left(\mathrm{Ca}^{2+}, \mathrm{H}^{+}, \mathrm{K}^{+}\right)$. Although the exact mechanism of pore opening and closing in the low conductance mode remains to be fully elucidated, this conductance state seems to be involved in various physiological responses. For example, in neural progenitor cells, repetitive MPTP openings are associated with neuronal differentiation, whereas CsA (which blocks mPTP flickering) induces the proliferation of the cell (Hou et al. 2012). In mouse embryonic fibroblasts, the reprogramming into a pluripotent state seems to be favored by transient openings of the MPTP. Indeed, these openings activate the demethylation of promoter regions of pluripotency genes (Ying et al. 2018). In contrast to the high conductance mode that irreversibly leads to the dissipation of the $\Delta \Psi$, the transient opening of the mPTP in the low conductance mode could participate to $\mathrm{Ca}^{2+}$ homeostasis by allowing the release of $\mathrm{Ca}^{2+}$ from mitochondria. The low conductance mode would thereby avoid mitochondrial $\mathrm{Ca}^{2+}$ overload without impairing mitochondrial bioenergetics associated with the release of metabolic substrates. In myocyte mitochondria, these opening events are indeed as- sociated to synchronized and CsA-dependent drops of matrix $\mathrm{Ca}^{2+}$ and mitochondrial membrane potential. In this system, these events are rare and remain localized in single mitochondria (Lu et al. 2016). These transient openings have also been indirectly observed in resting astrocytes, via the detailed observation of the local and stochastic increases of cytosolic $\mathrm{Ca}^{2+}$, which are inhibited by CsA (Fig. 3B; Agarwal et al. 2017).

As the MPTP in its low conductance mode is permeable to $\mathrm{Ca}^{2+}$, it is likely to alter cytosolic $\mathrm{Ca}^{2+}$ signaling. This is supported by experiments performed in HeLa cells: when the mPTP is inhibited by CsA, the $\mathrm{Ca}^{2+}$ oscillations in the cytosol are slightly slowed down (Wacquier et al. 2016). However, when mPTP activity is modulated by changing the expression level of the $\mathrm{C}$ subunit of the $\mathrm{F}_{1} \mathrm{~F}_{0}$-ATP synthase in HeLa cells, the mitochondrial $\mathrm{Ca}^{2+}$ fluxes are not significantly altered (De Marchi et al. 2014a). A plausible explanation for these apparently contradictory results is that the frequency of the oscillations is very sensitive to small $\mathrm{Ca}^{2+}$ changes, which may not be visible when measuring global fluxes at supramaximal histamine concentrations.

The dynamics of mPTP opening in its high conductance mode has been much studied in suspensions of mitochondria submitted to additions of exogenous $\mathrm{Ca}^{2+}$ (Fig. 3C). In these conditions, most of the $\mathrm{Ca}^{2+}$ added in the extra-mitochondrial medium is rapidly taken up by mitochondria, via the MCU. Successive $\mathrm{Ca}^{2+}$ additions finally lead to the rapid release of the sequestered $\mathrm{Ca}^{2+}$, probably when the level of mitochondrial $\mathrm{Ca}^{2+}$ reaches some threshold concentration leading to the opening of the mPTP in its high conductance mode. Interestingly, before this massive $\mathrm{Ca}^{2+}$ release, the basal level of $\mathrm{Ca}^{2+}$ slowly increases in the extramitochondrial medium. This increase may reflect the progressively increasing opening of the PTP in its low conductance mode and/or a decrease in $\Delta \Psi$. Interestingly, Ichas et al. (1997) even observed traveling waves of $\mathrm{Ca}^{2+}$ in preparations of mitochondria suspended in a gel. These waves were ascribed to mitochondrial CICR relying on the low conductance mode of the PTP (Oster 
B. Wacquier et al.

et al. 2011). How the regulations of the same pore in the two modes are related remains largely unknown. In a mathematical model, Oster et al. (2011) postulated two independent mechanisms of regulation for the two modes: an activation by matrix $\mathrm{pH}$ and by mitochondrial $\mathrm{Ca}^{2+}$ for the low and the high conductance states, respectively. Alternatively, to describe mitochondrial $\mathrm{Ca}^{2+}$ swelling in cardiac cells, it was hypothesized that the pore switches from the low to the high conductance mode if the extramitochondrial $\mathrm{Ca}^{2+}$ level increases (ChapaDubocq et al. 2018), which remains to be established experimentally.

\section{MITOCHONDRIAL METABOLISM}

Mitochondrial $\mathrm{Ca}^{2+}$ regulates bioenergetics in various ways. First, by increasing the NADH pool in mitochondria, which is necessary to establish the proton gradient. $\mathrm{Ca}^{2+}$ indeed activates several key enzymes of the Krebs cycle. By binding to the isocitrate and $\alpha$-ketoglutarate dehydrogenases, $\mathrm{Ca}^{2+}$ increases their affinities for their substrates without altering their maximal velocities. This increases the rates of reaction of these enzymes (Williams et al. 2015). $\mathrm{Ca}^{2+}$ also indirectly activates the pyruvate dehydrogenase. This enzyme is regulated by reversible phosphorylation, catalyzed by the pyruvate dehydrogenase phosphatase (PDP). When $\mathrm{Ca}^{2+}$ binds to the PDP the activity of this enzyme is increased, leading to the activation of pyruvate dehydrogenase (Denton 2009).

$\mathrm{Ca}^{2+}$ is also an activator of the malate-aspartate shuttle (MAS), which effectively allows translocation across the IMM of electrons from the NADH molecules produced in the cytosol during glycolysis (Fig. 1C). As the mitochondrial membrane is impermeable to $\mathrm{NADH}$, this coenzyme is first metabolized into malate that is conveyed into mitochondria by a $\alpha$-ketoglutarate-malate transporter (OGC). There, malate is converted into aspartate, which occurs together with the reduction of $\mathrm{NAD}^{+}$into NADH. $\mathrm{Ca}^{2+}$ regulates the activity of the aspartate-glutamate carrier (AGC), which is necessary for the replenishment of cytosolic malate. $\mathrm{Ca}^{2+}$ activates the two main AGCs with a high affinity (100 to 350
$\mathrm{nM}$, depending on the tissue): citrin (in heart or liver) and aralar (in brain, skeletal muscles, or heart). Thus, MAS activation is theoretically another pathway through which $\mathrm{Ca}^{2+}$ increases in the cytosol could stimulate mitochondrial metabolism. However, this pathway is only effective near basal $\mathrm{Ca}^{2+}$ levels. Indeed, at higher mitochondrial $\mathrm{Ca}^{2+}$, the activation of the Krebs cycle triggers a decrease in $\alpha$-ketoglutarate, which is a crucial metabolite of the MAS as it must be exported to allow the influx of malate (Contreras et al. 2007; Satrústegui et al. 2007).

Components of the ETC are also activated by $\mathrm{Ca}^{2+}$ : the activity of complexes I, III, and IV, which extrude protons out of the matrix, is increased twofold by $\mathrm{Ca}^{2+}$ (Territo et al. 2000; Glancy et al. 2013; Williams et al. 2015). However, it is not known if this regulation is performed by $\mathrm{Ca}^{2+}$ in the matrix or in the IMS (Territo et al. 2000; Glancy et al. 2013). Furthermore, $\mathrm{Ca}^{2+}$ is able to bind and activate the $\mathrm{F}_{1} \mathrm{~F}_{0^{-}}$ ATP synthase (Territo et al. 2000). As $\mathrm{Ca}^{2+}$ is a main activator of metabolism, it is not surprising to see that altering mitochondrial $\mathrm{Ca}^{2+}$ transporters impairs bioenergetics. LETM1 silencing induces lower mitochondrial $\mathrm{Ca}^{2+}$ levels and an impaired oxygen consumption (Doonan et al. 2014). In MICU1 mutant fibroblasts, the level of mitochondrial $\mathrm{Ca}^{2+}$ and dephosphorylated $\mathrm{PDH}$ are increased, although the level of ATP and the membrane potential remain unaffected (Bhosale et al. 2017).

Besides the direct activation of mitochondrial metabolism by $\mathrm{Ca}^{2+}$, the close interplay between $\mathrm{Ca}^{2+}$ signaling and metabolism is further complicated by the modulation of the rates of the $\mathrm{Ca}^{2+}$ transporters by $\Delta \Psi$. Strikingly, a large peak in cytosolic $\mathrm{Ca}^{2+}$ triggers a transient decrease of metabolic intermediates: a drop in mitochondrial/cytosolic ATP concentrations and in $\Delta \Psi$ is indeed observed in HeLa cells stimulated by histamine (Jouaville et al. 1999; Griffiths and Rutter 2009). This is probably because of a transient depolarization following the $\mathrm{Ca}^{2+}$ influx into mitochondria. This effect is rapidly counterbalanced by the activation of the Krebs cycle by $\mathrm{Ca}^{2+}$ (Wacquier et al. 2016). A similar transient decrease in ATP is observed in mouse eggs when the increase in cytosolic $\mathrm{Ca}^{2+}$ is in- 
Cytoplasmic and Mitochondrial Calcium Signaling

duced by the addition of the SERCA inhibitor thapsigargin (Campbell and Swann 2006). Conversely, in Xenopus oocytes, the injection of metabolic substrates induces drastic changes in cytosolic $\mathrm{Ca}^{2+}$ responses induced by $\mathrm{IP}_{3}$. These substrates allow the synchronization of the $\mathrm{Ca}^{2+}$ waves propagating in different regions of the egg. Synchronized waves display a higher amplitude and a larger velocity of propagation (Jouaville et al. 1995).

\section{SPATIAL ASPECTS}

The spatial intracellular distribution of mitochondria has a significant impact on $\mathrm{Ca}^{2+}$ signaling. For example, in mouse pancreatic acinar cells, the $\mathrm{Ca}^{2+}$ responses induced by an agonist at the apical pole of the cell remain localized in this area. This confinement is ascribed to a barrier of mitochondria, acting as a firewall by buffering $\mathrm{Ca}^{2+}$ (Tinel et al. 1999). In atrial cardiomyocytes, $\mathrm{Ca}^{2+}$ signals are generated at the periphery of the cell, but are not fully transmitted toward the cell center. If mitochondria are depolarized and thus unable to load $\mathrm{Ca}^{2+}$, the peripheral $\mathrm{Ca}^{2+}$ signal propagates in the cell and becomes global (Mackenzie et al. 2004).

The spatial arrangement of $\mathrm{Ca}^{2+}$ channels also needs to be considered: to transport $\mathrm{Ca}^{2+}$ efficiently, the MCU needs to be confronted with high $\mathrm{Ca}^{2+}$ concentrations, because of its affinity for this ion is low $\left(K_{D} \sim 2-10 \mu \mathrm{M}\right)$ (Mallilankaraman et al. 2012; Csordás et al. 2013; Paillard et al. 2017). However, the global (i.e., spatially averaged) concentration in the cytosol varies between $\sim 0.1 \mu \mathrm{M}$ at rest and $\sim 1 \mu \mathrm{M}$ at the peak of a $\mathrm{Ca}^{2+}$ oscillation. The low affinity of the MCU for $\mathrm{Ca}^{2+}$ prevents overloading mitochondria with $\mathrm{Ca}^{2+}$, but physiological $\mathrm{Ca}^{2+}$ sequestration requires specific mechanisms to reach sufficiently high $\mathrm{Ca}^{2+}$ concentrations to promote significant MCU activity. Hotspots of high $\mathrm{Ca}^{2+}$ concentration that promote $\mathrm{Ca}^{2+}$ uptake via the MCU can be achieved locally in regions known as mitochondria-associated membranes (MAMs). These are confined areas delimited by the membranes of the ER and the mitochondria, which are associated thanks to tethering proteins (Fig. 1B; Csordás et al. 2010). These zones contain
$\mathrm{Ca}^{2+}$ channels, notably $\mathrm{IP}_{3} \mathrm{R}, \mathrm{VDAC} 1$ (Szabadkai et al. 2006) or MCU (de la Fuente et al. 2016). Following a $\mathrm{Ca}^{2+}$ release by $\mathrm{IP}_{3} \mathrm{R}$, the $\mathrm{Ca}^{2+}$ signal first stays localized in the MAMs as this ion diffuses quite slowly in the cytoplasm. Thus, the $\mathrm{Ca}^{2+}$ concentrations are transiently higher in MAMs than in the rest of the cytoplasm, by a factor 5-10 (Csordás et al. 2010; Giacomello et al. 2010; Wacquier et al. 2017). These spatially restricted areas with high $\mathrm{Ca}^{2+}$ concentrations allow a better $\mathrm{Ca}^{2+}$ uptake by the MCU.

Accumulating evidence highlights the importance of these MAMs for physiological responses inside mitochondria but also on $\mathrm{Ca}^{2+}$ signaling in the cytosol. Indeed, mathematical modeling indicates that the drastically different kinetics of mitochondrial $\mathrm{Ca}^{2+}$ increases in intact cells and in suspensions of mitochondria can be ascribed to the absence of MAMs in the latter experimental conditions (Wacquier et al. 2017). At the MAMs, VDAC1 forms a complex with $\mathrm{IP}_{3} \mathrm{R}$ via the glucose-regulated protein 75 (GRP75) (Szabadkai et al. 2006). The formation of such a complex is favored by apoptotic stimuli, which pinpoints the importance of direct routes between the ER and mitochondria on the establishment of specific pathophysiological responses. It has been shown that overexpression of the three isoforms of VDAC increases physiological mitochondrial $\mathrm{Ca}^{2+}$ uptake, but that only the overexpression of VDAC1 enhances proapoptotic $\mathrm{Ca}^{2+}$ transfer (de Stefani et al. 2012; Monaco et al. 2015). Interestingly, the $\mathrm{Ca}^{2+}$ concentration and thus the rate of $\mathrm{Ca}^{2+}$ transport is also tuned by the size of the MAMs, in particular by the distance between the membranes of the ER and those of mitochondria (Qi et al. 2015). This space is tightly controlled by tethering proteins, such as the fetal and adult testis expressed 1 (FATE1), the protein kinase RNA-like ER kinase (PERK), or mitofusin 2 (Mfn2) (Naon and Scorrano 2014; Kerkhofs et al. 2017). For example, increasing FATE1 expression will enhance the distance between ER and mitochondria, and thereby decrease $\mathrm{Ca}^{2+}$ uptake, thus making cells more resistant against apoptotic stimuli. Such a mechanism is exploited in testicular cancer (Doghman-Bouguerra et al. 2016). On the other hand, knocking down 
B. Wacquier et al.

FATE1 sensitizes cells to death stimuli (Doghman-Bouguerra et al. 2016). Mfn2 has long been reported as a tethering protein, strengthening ER-mitochondria interactions. Mfn2 ablation leads to a lower $\mathrm{Ca}^{2+}$ uptake and to impaired energetic response (de Brito and Scorrano 2008; Chen et al. 2012). However, other studies pinpoint an increase in the number of close contacts between mitochondria and ER in Mfn2 knockedout cells, compared with wild-type cells. This is associated with an improved $\mathrm{Ca}^{2+}$ transfer at the ER-mitochondria interface. The low $\mathrm{Ca}^{2+}$ uptake observed in the first studies would occur because of a lower MCU expression and not because of any structural reason (Filadi et al. 2015, 2018). MAMs are also enriched in PERK proteins. The ablation of PERK induces weaker ER-mitochondria interactions and disturbs $\mathrm{Ca}^{2+}$ signaling (Verfaillie et al. 2012). Considering this link between MAMs and $\mathrm{Ca}^{2+}$ uptake, oncogenes and tumor suppressors may promote/prevent the survival of cancer cells by modulating MAMs size and hence the $\mathrm{Ca}^{2+}$ exchanges that act as life and death signals (Bittremieux et al. 2016; Danese et al. 2017). Tethering proteins thus constitute a target of choice for chemotherapeutics (Kerkhofs et al. 2018). In a general way, alterations of the spatial characteristics of the MAMs, and thus of $\mathrm{Ca}^{2+}$ dynamics in these microdomains, potentially lead to various pathological disorders, such as obesity, neurodegenerative diseases, or cancers (Marchi et al. 2017; Pinton 2018).

Intramitochondrial spatial aspects also play a key role in $\mathrm{Ca}^{2+}$ sequestration. In heart cells, the MCU, which is much less expressed than the NCLX, is mainly found in areas close to the junctional SR. Strikingly, the NCLX is excluded of these areas. There is thus a spatial separation of $\mathrm{Ca}^{2+}$ uptake and extrusion spots. This segregation could allow an effective mitochondrial response. Indeed, in a "mixed" situation in which the NCLX is also expressed near the junctional SR, the NCLX would extrude mitochondrial $\mathrm{Ca}^{2+}$ too fast. This limits the cost in terms of depolarization of the IMM, as the NCLX is electrogenic and induces depolarization of the membrane (de la Fuente et al. 2016, 2018).

\section{CONCLUDING REMARKS}

$\mathrm{Ca}^{2+}$ signaling and its physiological consequences have been intensively studied for decades. $\mathrm{Ca}^{2+}$ exchanges between the cytoplasm and the ER/SR play a primary role in this pathway. Although mitochondria are not constitutively loaded with $\mathrm{Ca}^{2+}$ in the absence of cell stimulation, various $\mathrm{Ca}^{2+}$ transporters allow for $\mathrm{Ca}^{2+}$ exchanges between the cytoplasm and these organelles (Csordás et al. 2013; Samanta et al. 2018; Shoshan-Barmatz et al. 2018). Thus, $\mathrm{Ca}^{2+}$ handling by mitochondria plays an important role in $\mathrm{Ca}^{2+}$ signaling of stimulated cells. Importantly, changes in the mitochondrial $\mathrm{Ca}^{2+}$ fluxes modify the frequency of cytosolic $\mathrm{Ca}^{2+}$ oscillations by reshaping the pacemakerlike $\mathrm{Ca}^{2+}$ increase that progressively sensitizes the $\mathrm{IP}_{3} \mathrm{R}$ (Hernández-SanMiguel et al. 2006; Wacquier et al. 2016). $\mathrm{Ca}^{2+}$ dynamics are also important for bioenergetics as mitochondrial $\mathrm{Ca}^{2+}$ uptake stimulates the production of ATP, which allows cells to cope with the increased energy demand created by stimuli. Reciprocally, mitochondrial metabolism can to some extent control $\mathrm{Ca}^{2+}$ signaling. In this review, we have mainly focused on the less studied impact of mitochondrial $\mathrm{Ca}^{2+}$ dynamics and metabolism on cytosolic $\mathrm{Ca}^{2+}$ signaling.

The regulation and molecular nature of the mitochondrial $\mathrm{Ca}^{2+}$ transporters have been well characterized, but some important questions are still open. For example, the nature of the mHCX and its participation in mitochondrial $\mathrm{Ca}^{2+}$ efflux in different cell types remain to be established (Austin et al. 2017). Similarly, the involvement of the MPTP in its low conductance mode for cellular $\mathrm{Ca}^{2+}$ homeostasis has been suggested (Lu et al. 2016; Wacquier et al. 2016; Agarwal et al. 2017), but the dynamical and quantitative aspects of this flux have still to be characterized. Such progress could also help deciphering the mechanisms that regulate the transition of this pore from the low- to the high-conductance mode.

Mitochondrial $\mathrm{Ca}^{2+}$ impacts on metabolism by activating the MAS shuttle, the Krebs cycle, and the ETC (Denton 2009; Williams et al. 2015). Computational modeling predicts that 
Cytoplasmic and Mitochondrial Calcium Signaling

in electrically nonexcitable cells such as HeLa cells or hepatocytes, the activation of the MAS shuttle by $\mathrm{Ca}^{2+}$ is only significant at low cytosolic $\mathrm{Ca}^{2+}$. At higher $\mathrm{Ca}^{2+}$ concentrations the activation of the glutamate-aspartate transporter is counterbalanced by the decrease in $\alpha$-ketoglutarate brought about by the activation of the Krebs cycle. The generality of this prediction remains to be tested experimentally. Other parameters affect the relation between $\mathrm{Ca}^{2+}$ increases and mitochondrial metabolism. First, changes in the ratio between cytosolic and mitochondrial $\mathrm{Ca}^{2+}$ concentrations modify $\Delta \Psi$, which controls all mitochondrial $\mathrm{Ca}^{2+}$ fluxes and reaction rates in the Krebs cycle and in the ETC. The intracellular spatial arrangement of mitochondria is also important. Various studies have indeed highlighted that mitochondria and ER are tightly coupled by microdomains (Csordás et al. 2010). The size of these areas is a crucial parameter because it can modulate $\mathrm{Ca}^{2+}$ uptake and induce either impaired bioenergetics or cellular death (Chen et al. 2012; Doghman-Bouguerra et al. 2016). The number, the size, and the dynamics of individual mitochondria are other characteristics of these organelles that require further investigation to fully understand the interplay between mitochondria and $\mathrm{Ca}^{2+}$ signaling in physiological and pathological conditions.

\section{ACKNOWLEDGMENTS}

G.D. is Research Director at the Belgian FNRS. G.D., L.C., and B.W. benefited from a WBIFrance exchange program (Wallonie-Bruxelles International, Fonds de la Recherche Scientifique, Ministère Français des Affaires étrangères et européennes, Ministère de l'Enseignement supérieur et de la Recherche dans le cadre des Partenariats Hubert Curien).

\section{REFERENCES}

Agarwal A, Wu PH, Hughes EG, Fukaya M, Tischfield MA, Langseth AJ, Wirtz D, Bergles DE. 2017. Transient opening of the mitochondrial permeability transition pore induces microdomain calcium transients in astrocyte processes. Neuron 93: 587-605.e7. doi:10.1016/j.neuron .2016 .12 .034
Antoniel M, Jones K, Antonucci S, Spolaore B, Fogolari F, Petronilli V, Giorgio V, Carraro M, Di Lisa F, Forte M, et al. 2018. The unique histidine in OSCP subunit of F-ATP synthase mediates inhibition of the permeability transition pore by acidic pH. EMBO Rep 19: 257-268. doi:10 .15252/embr.201744705

Austin S, Tavakoli M, Pfeiffer C, Seifert J, Mattarei A, de Stefani D, Zoratti M, Nowikovsky K. 2017. LETM1mediated $\mathrm{K}^{+}$and $\mathrm{Na}^{+}$homeostasis regulates mitochondrial $\mathrm{Ca}^{2+}$ efflux. Front Physiol 8: 839. doi:10.3389/fphys .2017 .00839

Baines CP, Kaiser RA, Sheiko T, Craigen WJ, Molkentin JD. 2007. Voltage-dependent anion channels are dispensable for mitochondrial-dependent cell death. Nat Cell Biol 9: 550-555. doi:10.1038/ncb1575

Baughman JM, Perocchi F, Girgis HS, Plovanich M, BelcherTimme CA, Sancak Y, Bao XR, Strittmatter L, Goldberger O, Bogorad RL, et al. 2011. Integrative genomics identifies MCU as an essential component of the mitochondrial calcium uniporter. Nature 476: 341-347. doi:10.1038/na ture10234

Bernardi P, Krauskopf A, Basso E, Petronilli V, BlachlyDyson E, Di Lisa F, Forte MA. 2006. The mitochondrial permeability transition from in vitro artifact to disease target. FEBS J 273: 2077-2099. doi:10.1111/j.1742-4658 .2006.05213.x

Berridge MJ, Bootman MD, Lipp P. 1998. Calcium-A life and death signal. Nature 395: 645-648. doi:10.1038/ 27094

Bhosale G, Sharpe JA, Koh A, Kouli A, Szabadkai G, Duchen MR. 2017. Pathological consequences of MICU1 mutations on mitochondrial calcium signalling and bioenergetics. Biochim Biophys Acta 1864: 1009-1017. doi:10 .1016/j.bbamcr.2017.01.015

Bittremieux M, Parys JB, Pinton P, Bultynck G. 2016. ER functions of oncogenes and tumor suppressors: Modulators of intracellular $\mathrm{Ca}^{2+}$ signaling. Biochim Biophys Acta 1863: 1364-1378. doi:10.1016/j.bbamcr.2016.01.002

Bonora M, Bononi A, de Marchi E, Giorgi C, Lebiedzinska M, Marchi S, Patergnani S, Rimessi A, Suski JM, Wojtala A, et al. 2013. Role of the $c$ subunit of the $F_{0}$ ATP synthase in mitochondrial permeability transition. Cell Cycle 12: 674-683. doi:10.4161/cc.23599

Bonora M, Morganti C, Morciano G, Pedriali G, Lebiedzinska-Arciszewska M, Aquila G, Giorgi C, Rizzo P, Campo G, Ferrari R, et al. 2017. Mitochondrial permeability transition involves dissociation of $\mathrm{F}_{1} \mathrm{~F}_{0}$ ATP synthase dimers and C-ring conformation. EMBO Rep 18: 1077-1089. doi:10.15252/embr.201643602

Booth DM, Enyedi B, Geiszt M, Várnai P, Hajnóczky G. 2016. Redox nanodomains are induced by and control calcium signaling at the ER-mitochondrial interface. Mol Cell 63: 240-248. doi:10.1016/j.molcel.2016.05.040

Brenner C, Moulin M. 2012. Physiological roles of the permeability transition pore. Circ Res 111: 1237-1247. doi: 10 .1161/CIRCRESAHA.112.265942

Bulluck H, Yellon DM, Hausenloy DJ. 2016. Reducing myocardial infarct size: Challenges and future opportunities. Heart 102: 341-348. doi:10.1136/heartjnl-2015-307855

Buntinas L, Gunter KK, Sparagna GC, Gunter TE. 2001. The rapid mode of calcium uptake into heart mitochondria (RaM): Comparison to RaM in liver mitochondria. Bio- 
B. Wacquier et al.

chim Biophys Acta 1504: 248-261. doi:10.1016/S00052728(00)00254-1

Campbell K, Swann K. 2006. $\mathrm{Ca}^{2+}$ oscillations stimulate an ATP increase during fertilization of mouse eggs. Dev Biol 298: 225-233. doi:10.1016/j.ydbio.2006.06.032

Chapa-Dubocq X, Makarov V, Javadov S. 2018. Simple kinetic model of mitochondrial swelling in cardiac cells. $J$ Cell Physiol 233: 5310-5321. doi:10.1002/jcp.26335

Chen Y, Csordás G, Jowdy C, Schneider TG, Csordás N, Wang W, Liu Y, Kohlhaas M, Meiser M, Bergem S, et al. 2012. Mitofusin 2-containing mitochondrial-reticular microdomains direct rapid cardiomyocyte bioenergetic responses via interorganelle $\mathrm{Ca}^{2+}$ crosstalk. Circ Res 111: 863-875. doi:10.1161/CIRCRESAHA.112.266585

Collins JC, Berridge MJ, Lipp P, Bootman MD. 2002. Mitochondria are morphologically and functionally heterogeneous within cells. EMBO J 21: 1616-1627. doi:10.1093/ emboj/21.7.1616

Contreras L, Gomez-Puertas P, Iijima M, Kobayashi K, Saheki T, Satrústegui J. 2007. Ca ${ }^{2+}$ activation kinetics of the two aspartate-glutamate mitochondrial carriers, aralar and citrin: Role in the heart malate-aspartate NADH shuttle. J Biol Chem 282: 7098-7106. doi:10.1074/jbc .M610491200

Contreras L, Drago I, Zampese E, Pozzan T. 2010. Mitochondria: The calcium connection. Biochim Biophys Acta 1797: 607-618. doi:10.1016/j.bbabio.2010.05.005

Csordás G, Hajnóczky G. 2009. SR/ER-mitochondrial local communication: Calcium and ROS. Biochim Biophys Acta 1787: 1352-1362. doi:10.1016/j.bbabio.2009.06.004

Csordás G, Thomas AP, Hajnóczky G. 1999. Quasi-synaptic calcium signal transmission between endoplasmic reticulum and mitochondria. $E M B O J$ 18: 96-108. doi:10 .1093/emboj/18.1.96

Csordás G, Várnai P, Golenár T, Roy S, Purkins G, Schneider TG, Balla T, Hajnóczky G. 2010. Imaging interorganelle contacts and local calcium dynamics at the ER-mitochondrial interface. Mol Cell 39: 121-132. doi:10.1016/j.molcel .2010 .06 .029

Csordás G, Golenár T, Seifert EL, Kamer KJ, Sancak Y, Perocchi F, Moffat C, Weaver D, de la Fuente Perez S, Bogorad R, et al. 2013. MICU1 controls both the threshold and cooperative activation of the mitochondrial $\mathrm{Ca}^{2+}$ uniporter. Cell Metab 17: 976-987. doi:10.1016/j.cmet.2013 .04 .020

Danese A, Patergnani S, Bonora M, Wieckowski MR, Previati M, Giorgi C, Pinton P. 2017. Calcium regulates cell death in cancer: Roles of the mitochondria and mitochondria-associated membranes (MAMs). Biochim Biophys Acta Bioenerg 1858: 615-627. doi:10.1016/j.bbabio.2017 .01 .003

de Brito OM, Scorrano L. 2008. Mitofusin 2 tethers endoplasmic reticulum to mitochondria. Nature 456: 605-611. doi:10.1038/nature07534

de la Fuente S, Fernandez-Sanz C, Vail C, Agra EJ, Holmstrom K, Sun J, Mishra J, Williams D, Finkel T, Murphy E, et al. 2016. Strategic positioning and biased activity of the mitochondrial calcium uniporter in cardiac muscle. J Biol Chem 291: 23343-23362. doi:10.1074/jbc.M116.755496

de la Fuente S, Lambert JP, Nichtova Z, Fernandez Sanz C, Elrod JW, Sheu SS, Csordás G. 2018. Spatial separation of mitochondrial calcium uptake and extrusion for energy- efficient mitochondrial calcium signaling in the heart. Cell Rep 24: 3099-3107.e4. doi:10.1016/j.celrep.2018.08 .040

De Marchi E, Bonora M, Giorgi C, Pinton P. 2014a. The mitochondrial permeability transition pore is a dispensable element for mitochondrial efflux. Cell Calcium 56: 1 13. doi:10.1016/j.ceca.2014.03.004

De Marchi U, Santo-Domingo J, Castelbou C, Sekler I, Wiederkehr A, Demaurex N. 2014b. NCLX protein, but not LETM1, mediates mitochondrial $\mathrm{Ca}^{2+}$ extrusion, thereby limiting $\mathrm{Ca}^{2+}$-induced $\mathrm{NAD}(\mathrm{P}) \mathrm{H}$ production and modulating matrix redox state. J Biol Chem 289: 20377-20385. doi:10.1074/jbc.M113.540898

Denton RM. 2009. Regulation of mitochondrial dehydrogenases by calcium ions. Biochim Biophys Acta 1787: 13091316. doi:10.1016/j.bbabio.2009.01.005

de Stefani D, Raffaello A, Teardo E, Szabò I, Rizzuto R. 2011 A $40 \mathrm{kDa}$ protein of the inner membrane is the mitochondrial calcium uniporter. Nature 476: 336-340. doi:10 $.1038 /$ nature 10230

de Stefani D, Bononi A, Romagnoli A, Messina A, de Pinto V, Pinton P, Rizzuto R. 2012. VDAC1 selectively transfers apoptotic $\mathrm{Ca}^{2+}$ signals to mitochondria. Cell Death Differ 19: 267-273. doi:10.1038/cdd.2011.92

Doghman-Bouguerra M, Granatiero V, Sbiera S, Sbiera I, Lacas-Gervais S, Brau F, Fassnacht M, Rizzuto R, Lalli E. 2016. FATE1 antagonizes calcium- and drug-induced apoptosis by uncoupling ER and mitochondria. $E M B O$ Rep 17: 1264-1280. doi:10.15252/embr.201541504

Doonan PJ, Chandramoorthy HC, Hoffman NE, Zhang X, Cárdenas C, Shanmughapriya S, Rajan S, Vallem S, Chen $\mathrm{X}$, Foskett JK, et al. 2014. LETM1-dependent mitochondrial $\mathrm{Ca}^{2+}$ flux modulates cellular bioenergetics and proliferation. FASEB J 28: 4936-4949. doi:10.1096/fj.14256453

Dupont G, Combettes L, Bird GS, Putney JW. 2011. Calcium oscillations. Cold Spring Harb Perspect Biol 3: a004226. doi:10.1101/cshperspect.a004226

El-Hattab AW, Suleiman J, Almannai M, Scaglia F. 2018. Mitochondrial dynamics: Biological roles, molecular machinery, and related diseases. Mol Genet Metab doi:10 .1016/j.ymgme.2018.10.003

Feissner RF, Skalska J, Gaum WE, Sheu SS. 2009. Crosstalk signaling between mitochondrial $\mathrm{Ca}^{2+}$ and ROS. Front Biosci 14: 1197-1218. doi:10.2741/3303

Fieni F, Bae Lee S, Jan YN, Kirichok Y. 2012. Activity of the mitochondrial calcium uniporter varies greatly between tissues. Nat Commun 3: 1317. doi:10.1038/ncomms 2325

Filadi R, Greotti E, Turacchio G, Luini A, Pozzan T, Pizzo P. 2015. Mitofusin 2 ablation increases endoplasmic reticulum-mitochondria coupling. Proc Natl Acad Sci 112: E2174-E2181. doi:10.1073/pnas.1504880112

Filadi R, Greotti E, Pizzo P. 2018. Highlighting the endoplasmic reticulum-mitochondria connection: Focus on mitofusin 2. Pharmacol Res 128: 42-51. doi:10.1016/j.phrs .2018 .01 .003

Gadicherla AK, Wang N, Bulic M, Agullo-Pascual E, Lissoni A, de Smet M, Delmar M, Bultynck G, Krysko DV, Camara A, et al. 2017. Mitochondrial Cx43 hemichannels contribute to mitochondrial calcium entry and cell death in the heart. Basic Res Cardiol 27: 112-127. doi:10.1007/ s00395-017-0618-1 
Giacomello M, Drago I, Bortolozzi M, Scorzeto M, Gianelle A, Pizzo P, Pozzan T. 2010. $\mathrm{Ca}^{2+}$ hot spots on the mitochondrial surface are generated by $\mathrm{Ca}^{2+}$ mobilization from stores, but not activation of store-operated $\mathrm{Ca}^{2+}$ channels. Mol Cell 38: 280-290. doi:10.1016/j.molcel 2010.04 .003

Giorgi C, Marchi S, Pinton P. 2018. The machineries, regulation and cellular functions of mitochondrial calcium. Nat Rev Mol Cell Biol 19: 713-730. doi:10.1038/s41580018-0052-8

Giorgio V, Bisetto E, Soriano ME, Dabbeni-Sala F, Basso E, Petronilli V, Forte MA, Bernardi P, Lippe G. 2009. Cyclophilin $\mathrm{D}$ modulates mitochondrial $\mathrm{F}_{0} \mathrm{~F}_{1}$-ATP synthase by interacting with the lateral stalk of the complex. J Biol Chem 284: 33982-33988. doi:10.1074/jbc.M109.020115

Giorgio V, von Stockum S, Antoniel M, Fabbro A, Fogolari F, Forte M, Glick GD, Petronilli V, Zoratti M, Szabó I, et al. 2013. Dimers of mitochondrial ATP synthase form the permeability transition pore. Proc Natl Acad Sci 110: 5887-5892. doi:10.1073/pnas.1217823110

Giorgio V, Burchell V, Schiavone M, Bassot C, Minervini G, Petronilli V, Argenton F, Forte M, Tosatto S, Lippe G, et al. 2017. $\mathrm{Ca}^{2+}$ binding to F-ATP synthase $\beta$ subunit triggers the mitochondrial permeability transition. $E M B O$ Rep 18: 1065-1076. doi:10.15252/embr.201643354

Giorgio V, Guo L, Bassot C, Petronilli V, Bernardi P. 2018. Calcium and regulation of the mitochondrial permeability transition. Cell Calcium 70: 56-63. doi:10.1016/j.ceca 2017.05.004

Glancy B, Willis WT, Chess DJ, Balaban RS. 2013. Effect of calcium on the oxidative phosphorylation cascade in skeletal muscle mitochondria. Biochemistry 52: 2793-2809. doi:10.1021/bi3015983

Gonze D, Gérard C, Wacquier B, Woller A, Tosenberger A, Goldbeter A, Dupont G. 2018. Modeling-based investigation of the effect of noise in cellular systems. Front Mol Biosci 5: 34. doi:10.3389/fmolb.2018.00034

Griffiths EJ, Rutter GA. 2009. Mitochondrial calcium as a key regulator of mitochondrial ATP production in mammalian cells. Biochim Biophys Acta 1787: 1324-1333. doi:10.1016/j.bbabio.2009.01.019

Hajnóczky G, Robb-Gaspers LD, Seitz MB, Thomas AP. 1995. Decoding of cytosolic calcium oscillations in the mitochondria. Cell 82: 415-424. doi:10.1016/0092-8674 (95)90430-1

He J, Ford HC, Carroll J, Ding S, Fearnley IM, Walker JE. 2017. Persistence of the mitochondrial permeability transition in the absence of subunit c of human ATP synthase. Proc Natl Acad Sci 114: 3409-3414. doi:10.1073/pnas 1702357114

Hernández-SanMiguel E, Vay L, Santo-Domingo J, Lobatón CD, Moreno A, Montero M, Alvarez J. 2006. The mitochondrial $\mathrm{Na}^{+} / \mathrm{Ca}^{2+}$ exchanger plays a key role in the control of cytosolic $\mathrm{Ca}^{2+}$ oscillations. Cell Calcium 40: 53-61. doi:10.1016/j.ceca.2006.03.009

Hou Y, Ouyang X, Wan R, Cheng H, Mattson MP, Cheng A. 2012. Mitochondrial superoxide production negatively regulates neural progenitor proliferation and cerebral cortical development. Stem Cells 30: 2535-2547. doi:10 $.1002 /$ stem. 1213

Hunter DR, Haworth RA. 1979a. The $\mathrm{Ca}^{2+}$-induced membrane transition in mitochondria. I: The protective mech- anisms. Arch Biochem Biophys 195: 453-459. doi:10 .1016/0003-9861(79)90371-0

Hunter DR, Haworth RA. 1979b. The $\mathrm{Ca}^{2+}$-induced membrane transition in mitochondria. III: Transitional $\mathrm{Ca}^{2+}$ release. Arch Biochem Biophys 195: 468-477. doi:10.1016/ 0003-9861(79)90373-4

Hunter DR, Haworth RA. 1979c. The $\mathrm{Ca}^{2+}$-induced membrane transition in mitochondria. II: Nature of the $\mathrm{Ca}^{2+}$ trigger site. Arch Biochem Biophys 195: 460-467. doi:10 .1016/0003-9861(79)90372-2

Hunter DR, Haworth RA, Southard JH. 1976. Relationship between configuration, function, and permeability in calcium-treated mitochondria. J Biol Chem 251: 5069-5077.

Hwang M-S, Schwall CT, Pazarentzos E, Datler C, Alder NN, Grimm S. 2014. Mitochondrial Ca ${ }^{2+}$ influx targets cardiolipin to disintegrate respiratory chain complex II for cell death induction. Cell Death Differ 21: 1733-1745. doi:10 $.1038 /$ cdd.2014.84

Ichas F, Jouaville L, Mazat JP. 1997. Mitochondria are excitable organelles capable of generating and conveying electrical and calcium signals. Cell 89: 1145-1153. doi:10 .1016/S0092-8674(00)80301-3

Ishii K, Hirose K, Iino M. 2006. $\mathrm{Ca}^{2+}$ Shuttling between endoplasmic reticulum and mitochondria underlying $\mathrm{Ca}^{2+}$ oscillations. EMBO Rep 7: 390-396. doi:10.1038/sj .embor.7400620

Jakob R, Beutner G, Sharma VK, Duan Y, Gross RA, Hurst S, Jhun BS, O-Uchi J, Sheu SS. 2014. Molecular and functional identification of a mitochondrial ryanodine receptor in neurons. Neurosci Lett 575: 7-12. doi:10.1016/j .neulet.2014.05.026

Joseph SK, Young MP, Alzayady K, Yule DI, Ali M, Booth DM, Hajnóczky G. 2018. Redox regulation of type-I inositol trisphosphate receptors in intact mammalian cells. $J$ Biol Chem 293: 17464-17476. doi:10.1074/jbc.RA118 .005624

Jouaville LS, Ichas F, Holmuhamedov EL, Camacho P, Lechleiter JD. 1995. Synchronization of calcium waves by mitochondrial substrates in Xenopus Laevis oocytes. Nature 377: 438-441. doi:10.1038/377438a0

Jouaville LS, Pinton P, Bastianutto C, Rutter GA, Rizzuto R. 1999. Regulation of mitochondrial ATP synthesis by calcium: Evidence for a long-term metabolic priming. Proc Natl Acad Sci 96: 13807-13812. doi:10.1073/pnas.96.24 .13807

Kerkhofs M, Giorgi C, Marchi S, Seitaj B, Parys JB, Pinton P, Bultynck G, Bittremieux M. 2017. Alterations in $\mathrm{Ca}^{2+}$ signalling via ER-mitochondria contact site remodelling in cancer. Adv Exp Med Biol 997: 225-254. doi:10.1007/ 978-981-10-4567-7_17

Kerkhofs M, Bittremieux M, Morciano G, Giorgi C, Pinton P, Parys JB, Bultynck G. 2018. Emergin molecular mechanisms in chemotherapy: $\mathrm{Ca}^{2+}$ signaling at the mitochondria-associated endoplasmic reticulum membranes. Cell Death Dis 9: 334. doi:10.1038/s41419-017-0179-0

Kim B, Takeuchi A, Koga O, Hikida M, Matsuoka S. 2013. Mitochondria $\mathrm{Na}^{+}-\mathrm{Ca}^{2+}$ exchange in cardiomyocytes and lymphocytes. Adv Exp Med Biol 961: 193-201. doi:10.1007/978-1-4614-4756-6_16

Kokoszka JE, Waymire KG, Levy SE, Sligh JE, Cai J, Jones DP, MacGregor GR, Wallace DC. 2004. The ADP/ATP translocator is not essential for the mitochondrial perme- 
B. Wacquier et al.

ability transition pore. Nature 427: 461-465. doi:10.1038/ nature02229

Lu X, Kwong JQ, Molkentin JD, Bers DM. 2016. Individual cardiac mitochondria undergo rare transient permeability transition pore openings. Circ Res 118: 834-841. doi:10 .1161/CIRCRESAHA.115.308093

Mackenzie L, Roderick HL, Berridge MJ, Conway SJ, Bootman MD. 2004. The spatial pattern of atrial cardiomyocyte calcium signalling modulates contraction. J Cell Sci 117: 6327-6337. doi:10.1242/jcs.01559

Mallilankaraman K, Doonan P, Cárdenas C, Chandramoorthy HC, Müller M, Miller R, Hoffman NE, Gandhirajan RK, Molgó J, Birnbaum MJ, et al. 2012. MICU1 is an essential gatekeeper for MCU-mediated mitochondrial $\mathrm{Ca}^{2+}$ uptake that regulates cell survival. Cell 151: 630644. doi:10.1016/j.cell.2012.10.011

Mammucari C, Raffaello A, Reane DV, Gherardi G, de Mario A, Rizzuto R. 2018. Mitochondrial calcium uptake in organ physiology: From molecular mechanism to animal models. Pflüg Arch Eur J Phys 470: 1165-1179. doi:10 .1007/s00424-018-2123-2

Marchi S, Bittremieux M, Missiroli S, Morganti C, Patergnani S, Sbano L, Rimessi A, Kerkhofs M, Parys JB, Bultynck G, et al. 2017. Endoplasmic reticulum-mitochondria communication through $\mathrm{Ca}^{2+}$ signaling: The importance of mitochondria-associated membranes (MAMs). Adv Exp Med 997: 49-67. doi:10.1007/978981-10-4567-7_4

Meissner G. 1981. Calcium transport and monovalent cation and proton fluxes in sarcoplasmic reticulum vesicles. $J$ Biol Chem 256: 636-643.

Mishra P. 2016. Interfaces between mitochondrial dynamics and disease. Cell Calcium 60: 190-198. doi:10.1016/j.ceca .2016 .05 .004

Monaco G, Decrock E, Arbel N, van Vliet AR, La Rovere RM, de Smedt H, Parys JB, Agostinis P, Leybaert L, ShoshanBarmatz V, et al. 2015. The BH4 domain of anti-apoptotic Bcl-XL, but not that of the related Bcl-2, limits the voltage-dependent anion channel 1 (VDAC1)-mediated transfer of pro-apoptotic $\mathrm{Ca}^{2+}$ signals to mitochondria. $J$ Biol Chem 290: 9150-9161. doi:10.1074/jbc.M114 .622514

Morciano G, Giorgi C, Bonora M, Punzetti S, Pavasini R, Wieckowski MR, Campo G, Pinton P. 2015. Molecular identity of the mitochondrial permeability transition pore and its role in ischemia-reperfusion injury. $J$ Mol Cell Cardiol 78: 142-153. doi:10.1016/j.yjmcc.2014.08.015

Morciano G, Preti D, Pedriali G, Aquila G, Missiroli S, Fantinati A, Caroccia N, Pacifico S, Bonora M, Talarico A, et al. 2018. Discovery of novel 1,3,8-triazaspiro[4.5]decane derivatives that target the $c$ subunit of $F_{1} / F_{0}$-adenosine triphosphate (ATP) synthase for the treatment of reperfusion damage in myocardial infarction. J Med Chem 61: 7131-7143. doi:10.1021/acs.jmedchem.8b00278

Murphy MP, Hartley RC. 2018. Mitochondria as a therapeutic target for common pathologies. Nat Rev Drug Discov doi:10.1038/nrd.2018.174

Naon D, Scorrano L. 2014. At the right distance: ER-mitochondria juxtaposition in cell life and death. Biochim Biophys Acta 1843: 2184-2194. doi:10.1016/j.bbamcr .2014 .05 .011
Nemani N, Shanmughapriya S, Madesh M. 2018. Molecular regulation of MCU: Implications in physiology and disease. Cell Calcium 74: 86-93. doi:10.1016/j.ceca.2018.06 .006

Nicholls DG, Chalmers S. 2004. The integration of mitochondrial calcium transport and storage. J Bioenerg Biomembr 36: 277-281. doi:10.1023/B:JOBB.0000041753 $.52832 . \mathrm{f3}$

Oster A, Thomas B, Terman D, Fall C. 2011. The low conductance mitochondrial permeability transition pore confers excitability and CICR wave propagation in a computational model. J Theor Biol 273: 216-231. doi:10.1016/ j.jtbi.2010.12.023

Paillard M, Csordás G, Szanda G, Golenár T, Debattisti V, Bartok A, Wang N, Moffat C, Seifert EL, Spät A, et al. 2017. Tissue-specific mitochondrial decoding of cytoplasmic $\mathrm{Ca}^{2+}$ signals is controlled by the stoichiometry of MICU1/2 and MCU. Cell Rep 18: 2291-2300. doi:10 $.1016 /$ j.celrep.2017.02.032

Palty R, Silverman WF, Hershfinkel M, Caporale T, Sensi SL, Parnis J, Nolte C, Fishman D, Shoshan-Barmatz V, Herrmann S, et al. 2010. NCLX is an essential component of mitochondrial $\mathrm{Na}^{+} / \mathrm{Ca}^{2+}$ exchange. Proc Natl Acad Sci 107: 436-441. doi:10.1073/pnas.0908099107

Patel S, Muallem S. 2011. Acidic $\mathrm{Ca}^{2+}$ stores come to the fore. Cell Calcium 50: 109-112. doi:10.1016/j.ceca.2011.03.009

Patron M, Checchetto V, Raffaello A, Teardo E, Vecellio Reane D, Mantoan M, Granatiero V, Szabò I, de Stefani D, Rizzuto R. 2014. MICU1 and MICU2 finely tune the mitochondrial $\mathrm{Ca}^{2+}$ uniporter by exerting opposite effects on MCU activity. Mol Cell 53: 726-737. doi:10.1016/j .molcel.2014.01.013

Penna E, Espino J, de Stefani D, Rizzuto R. 2018. The MCU complex in cell death. Cell Calcium 69: 73-80. doi:10 $.1016 /$ j.ceca.2017.08.008

Pérez MJ, Quintanilla RA. 2017. Development or disease: Duality of the mitochondrial permeability transition pore. Dev Biol 426: 1-7. doi:10.1016/j.ydbio.2017.04.018

Pinton P. 2018. Mitochondria-associated membranes (MAMs) and pathologies. Cell Death Dis 9: 413. doi:10 .1038/s41419-018-0424-1

Potter JS, Ward EN. 1942. Mitochondria in lymphocytes of normal and leukemic mice. Cancer Res 2: 655-659.

Qi H, Li L, Shuai J. 2015. Optimal microdomain crosstalk between endoplasmic reticulum and mitochondria for $\mathrm{Ca}^{2+}$ oscillations. Sci Rep 5: 7984. doi:10.1038/srep07984

Rasol A, Sciacovelli M, Chiara F, Pantic B, Brusilow WS Bernardi P. 2010. Activation of mitochondrial ERK protects cancer cells from death through inhibition of the permeability transition. Proc Natl Acad Sci 107: 726731. doi:10.1073/pnas.0912742107

Repsold L, Joubert AM. 2018. Eryptosis: An erythrocyte's suicidal type of cell death. BioMed Res Int 2018: 1-10. doi:10.1155/2018/9405617

Rizzuto R, Pinton P, Carrington W, Fay FS, Fogarty KE, Lifshitz LM, Tuft RA, Pozzan T. 1998. Close contacts with the endoplasmic reticulum as determinants of mitochondrial $\mathrm{Ca}^{2+}$ responses. Science 280: 1763-1766. doi:10.1126/science.280.5370.1763

Rizzuto R, de Stefani D, Raffaello A, Mammucari C. 2012. Mitochondria as sensors and regulators of calcium signal- 
ling. Nat Rev Mol Cell Biol 13: 566-578. doi:10.1038/ nrm3412

Samanta K, Douglas S, Parekh AB. 2014. Mitochondrial calcium uniporter MCU supports cytoplasmic $\mathrm{Ca}^{2+}$ oscillations, store-operated $\mathrm{Ca}^{2+}$ entry and $\mathrm{Ca}^{2+}$-dependent gene expression in response to receptor stimulation. PLoS ONE 9: e101188. doi:10.1371/journal.pone.0101188

Samanta K, Mirams GR, Parekh AB. 2018. Sequential forward and reverse transport of the $\mathrm{Na}^{+} \mathrm{Ca}^{2+}$ exchanger generates $\mathrm{Ca}^{2+}$ oscillations within mitochondria. Nat Commun 9: 156. doi:10.1038/s41467-017-02638-2

Satrústegui J, Pardo B, del Arco A. 2007. Mitochondrial transporters as novel targets for intracellular calcium signaling. Physiol Rev 87: 29-67. doi:10.1152/physrev.00005 .2006

Sedova M, Dedkova EN, Blatter LA. 2006. Integration of rapid cytosolic $\mathrm{Ca}^{2+}$ signals by mitochondria in cat ventricular myocytes. Am J Physiol Cell Physiol 291: C840C850. doi:10.1152/ajpcell.00619.2005

Shao J, Fu Z, Ji Y, Guan X, Ding Z, Yang X, Cong Y, Shen Y. 2016. Leucine zipper-EF-hand containing transmembrane protein 1 (LETM1) forms a $\mathrm{Ca}^{2+} / \mathrm{H}^{+}$antiporter. Sci Rep 6: 34174. doi:10.1038/srep34174

Shimizu H, Schredelseker J, Huang J, Lu K, Naghdi S, Lu F, Franklin S, Fiji HDG, Wang K, Zhu H, et al. 2015. Mitochondrial $\mathrm{Ca}^{2+}$ uptake by the voltage-dependent anion channel 2 regulates cardiac rhythmicity. eLife 4: e04801. doi:10.7554/eLife.04801

Shoshan-Barmatz V, Krelin Y, Shteinfer-Kuzmine A. 2018. VDAC1 functions in $\mathrm{Ca}^{2+}$ homeostasis and cell life and death in health and disease. Cell Calcium 69: 81-100. doi:10.1016/j.ceca.2017.06.007

Suzuki J, Kanemaru K, Ishii K, Ohkura M, Okubo Y, Iino M. 2014. Imaging intraorganellar $\mathrm{Ca}^{2+}$ at subcellular resolution using CEPIA. Nat Commun 5: 4153. doi:10.1038/ ncomms5153

Szabadkai G, Bianchi K, Várnai P, de Stefani D, Wieckowski MR, Cavagna D, Nagy AI, Balla T, Rizzuto R. 2006. Chaperone-mediated coupling of endoplasmic reticulum and mitochondrial $\mathrm{Ca}^{2+}$ channels. J Cell Biol 175: 901-911. doi:10.1083/jcb.200608073

Szabo I, Zoratti M. 2014. Mitochondrial channels: Ion fluxes and more. Physiol Rev 94: 519-608. doi:10.1152/physrev .00021 .2013

Tadic V, Prell T, Lautenschlaeger J, Grosskreutz J. 2014. The ER mitochondria calcium cycle and ER stress response as therapeutic targets in amyotrophic lateral sclerosis. Front Cell Neurosci 8: 147. doi:10.3389/fncel.2014.00147

Tan W, Colombini M. 2007. VDAC closure increases calcium ion flux. Biochim Biophys Acta 1768: 2510-2515. doi:10.1016/j.bbamem.2007.06.002

Territo PR, Mootha VK, French SA, Balaban RS. 2000. $\mathrm{Ca}^{2+}$ activation of heart mitochondrial oxidative phosphorylation: Role of the $\mathrm{F}_{0} / \mathrm{F}_{1}$-ATPase. Am J Physiol Cell Physiol 278: C423-C435. doi:10.1152/ajpcell.2000.278.2.C423

Tinel H, Cancela JM, Mogami H, Gerasimenko JV, Gerasimenko OV, Tepikin AV, Petersen OH. 1999. Active mitochondria surrounding the pancreatic acinar granule region prevent spreading of inositol trisphosphate-evoked local cytosolic $\mathrm{Ca}^{2+}$ signals. EMBO J 18: 4999-5008. doi:10.1093/emboj/18.18.4999
Tsai MF, Jiang D, Zhao L, Clapham D, Miller C. 2014. Functional reconstitution of the mitochondrial $\mathrm{Ca}^{2+} / \mathrm{H}^{+}$antiporter Letm1. J Gen Physiol 143: 67-73. doi:10.1085/jgp .201311096

Verfaillie T, Rubio N, Garg AD, Bultynck G, Rizzuto R, Decuypere J-P, Piette J, Linehan C, Gupta S, Samali A, et al. 2012. PERK is required at the ER-mitochondrial contact sites to convey apoptosis after ROS-based ER stress. Cell Death Diff 19: 1880-1891. doi:10.1038/cdd .2012 .74

Wacquier B, Combettes L, Van Nhieu GT, Dupont G. 2016. Interplay between intracellular $\mathrm{Ca}^{2+}$ oscillations and $\mathrm{Ca}^{2}$ ${ }^{+}$-stimulated mitochondrial metabolism. Sci Rep 6: 19316. doi:10.1038/srep19316

Wacquier B, Romero Campos HE, González-Vélez V, Combettes L, Dupont G. 2017. Mitochondrial $\mathrm{Ca}^{2+}$ dynamics in cells and suspensions. FEBS J 284: 4128-4142. doi:10.1111/febs.14296

Wang S, Xiao W, Shan S, Jiang C, Chen M, Zhang Y, Lü S, Chen J, Zhang C, Chen Q, et al. 2012. Multi-patterned dynamics of mitochondrial fission and fusion in a living cell. PLoS ONE 7: e19879. doi:10.1371/journal.pone .0019879

Wang W, Karamanlidis G, Tian R. 2016. Novel targets for mitochondrial medicine. Sci Transl Med 8: 326rv3. doi:10 $.1126 /$ scitranslmed.aac7410

Wang P, Fernandez-Sanz C, Wang W, Sheu SS. 2018. Why don't mice lacking the mitochondrial $\mathrm{Ca}^{2+}$ uniporter experience an energy crisis? MCU and heart bioenergetics. J Physiol doi:10.1113/JP276636

Weibel ER, Stäubli W, Gnägi HR, Hess FA. 1969. Correlated morphometric and biochemical studies on the liver cell. $J$ Cell Biol 42: 68-91. doi:10.1083/jcb.42.1.68

Williams GSB, Boyman L, Lederer WJ. 2015. Mitochondrial calcium and the regulation of metabolism in the heart. $J$ Mol Cell Cardiol 78: 35-45. doi:10.1016/j.yjmcc.2014.10 .019

Wingrove DE, Gunter TE. 1986. Kinetics of mitochondrial calcium transport. II: A kinetic description of the sodiumdependent calcium efflux mechanism of liver mitochondria and inhibition by ruthenium red and by tetraphenylphosphonium. J Biol Chem 261: 15166-15171.

Xie A, Zhou A, Liu H, Shi G, Liu M, Boheler KR, Dudley SC Jr. 2018. Mitochondrial $\mathrm{Ca}^{2+}$ flux modulates spontaneous electrical activity in ventricular cardiomyocytes. PLOS ONE 13: e0200448. doi:10.1371/journal.pone .0200448

Ying Z, Xiang G, Zheng L, Tang H, Duan L, Lin X, Zhao Q, Chen K, Wu Y, Xing G, et al. 2018. Short-term mitochondrial permeability transition pore opening modulates histone lysine methylation at the early phase of somatic cell reprogramming. Cell Metab doi:10.1016/j.cmet.2018.08 .001

Yu S, Zheng S, Leng J, Wang S, Zhao T, Liu J. 2016. Inhibition of mitochondrial calcium uniporter protects neurocytes from ischemia/reperfusion injury via the inhibition of excessive mitophagy. Neurosci Lett 628: 24-29. doi:10 .1016/j.neulet.2016.06.012

Zemirli N, Morel E, Molino D. 2018. Mitochondrial dynamics in basal and stressful conditions. Int J Mol Sci 19: 564. doi:10.3390/ijms19020564 


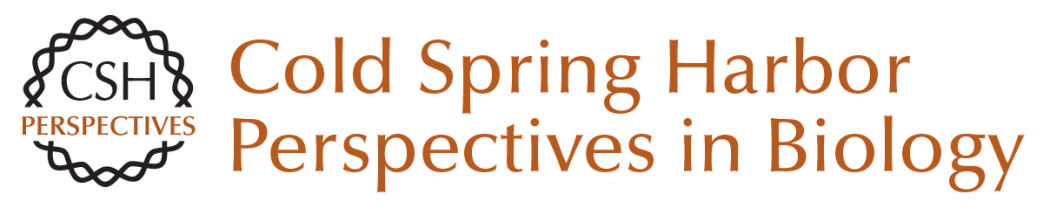

\section{Cytoplasmic and Mitochondrial Calcium Signaling: A Two-Way Relationship}

Benjamin Wacquier, Laurent Combettes and Geneviève Dupont

Cold Spring Harb Perspect Biol 2019; doi: 10.1101/cshperspect.a035139 originally published online May 20, 2019

\section{Subject Collection Calcium Signaling}

The Endoplasmic Reticulum-Plasma Membrane Junction: A Hub for Agonist Regulation of $\mathrm{Ca}^{2+}$ Entry

Hwei Ling Ong and Indu Suresh Ambudkar

Calcium-Handling Defects and Neurodegenerative

Disease

Sean Schrank, Nikki Barrington and Grace E. Stutzmann

Lysosomal $\mathrm{Ca}^{2+}$ Homeostasis and Signaling in Health and Disease

Emyr Lloyd-Evans and Helen Waller-Evans

$\mathrm{Ca}^{2+}$ Signaling in Exocrine Cells

Malini Ahuja, Woo Young Chung, Wei-Yin Lin, et al.

Functional Consequences of Calcium-Dependent Synapse-to-Nucleus Communication: Focus on Transcription-Dependent Metabolic Plasticity Anna M. Hagenston, Hilmar Bading and Carlos Bas-Orth

Identifying New Substrates and Functions for an Old Enzyme: Calcineurin

Jagoree Roy and Martha S. Cyert

Fundamentals of Cellular Calcium Signaling: A

Primer

Martin D. Bootman and Geert Bultynck
Primary Active $\mathrm{Ca}^{2+}$ Transport Systems in Health and Disease

Jialin Chen, Aljona Sitsel, Veronick Benoy, et al.

Signaling through $\mathrm{Ca}^{2+}$ Microdomains from

Store-Operated CRAC Channels

Pradeep Barak and Anant B. Parekh

Structural Insights into the Regulation of $\mathrm{Ca}^{2+}$ /Calmodulin-Dependent Protein Kinase II (CaMKII) Moitrayee Bhattacharyya, Deepti Karandur and John Kuriyan

Store-Operated Calcium Channels: From Function to Structure and Back Again Richard S. Lewis

Bcl-2-Protein Family as Modulators of $\mathrm{IP}_{3}$

Receptors and Other Organellar $\mathrm{Ca} 2+$ Channels Hristina Ivanova, Tim Vervliet, Giovanni Monaco, et al.

Calcium Signaling in Cardiomyocyte Function Guillaume Gilbert, Kateryna Demydenko, Eef Dries, et al.

Cytosolic $\mathrm{Ca}^{2+}$ Buffers Are Inherently $\mathrm{Ca}^{2+}$ Signal Modulators Beat Schwaller

For additional articles in this collection, see http://cshperspectives.cshlp.org/cgi/collection/

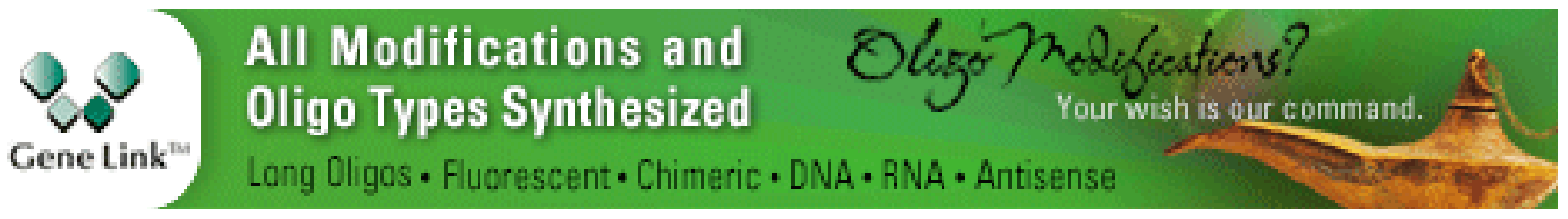


Role of Two-Pore Channels in Embryonic Development and Cellular Differentiation Sarah E. Webb, Jeffrey J. Kelu and Andrew L. Miller

\section{Organellar Calcium Handling in the Cellular \\ Reticular Network}

Wen-An Wang, Luis B. Agellon and Marek Michalak

For additional articles in this collection, see http://cshperspectives.cshlp.org/cgi/collection/

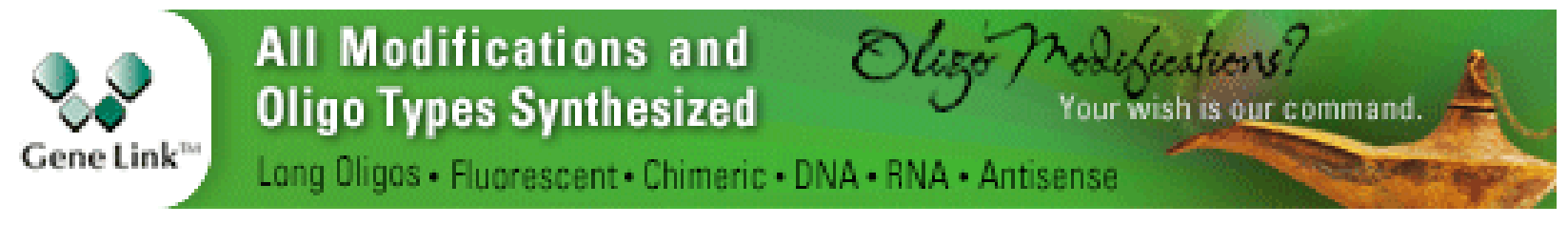

Copyright @ 2019 Cold Spring Harbor Laboratory Press; all rights reserved 